معارف وتطبيق الزراع للتوصيات الإرشادية الزراعية في مجال الإنتاج الحيواني في بعض قرى مركز أشمون

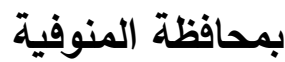

إسماعيل عبد المالك محمد'

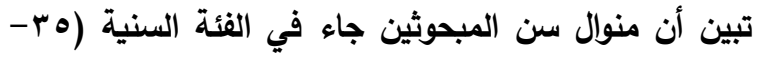

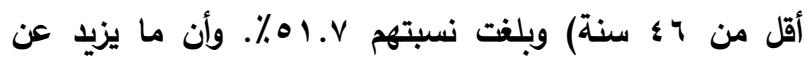

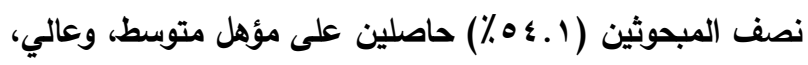

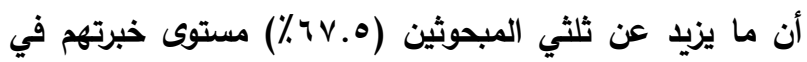

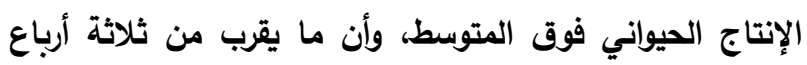

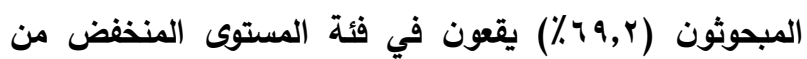

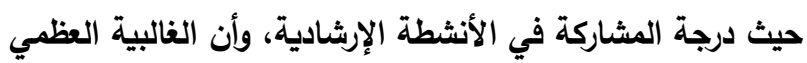

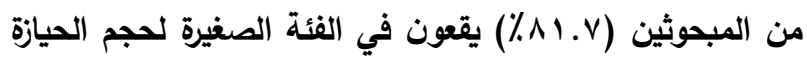

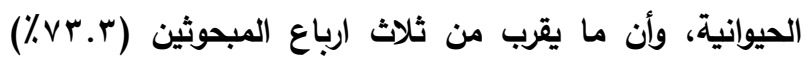

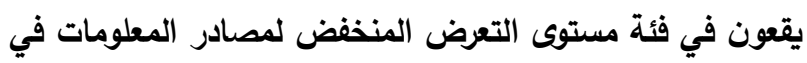
مجال الإنتاج الحيواني.

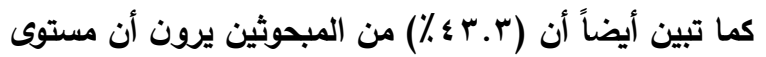

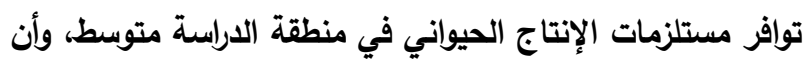
الغالبية العظمى من المبحوثين (ץ.؟ 9\%) يرون أن مستوى توافر

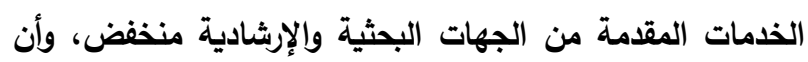

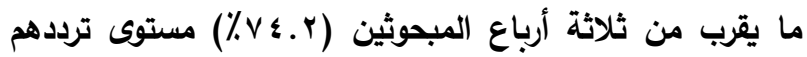

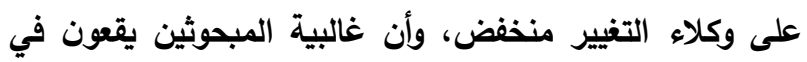
فئة مستوى المعرفة فوق المتوسط بالتوصيات الفنية الإرشادية

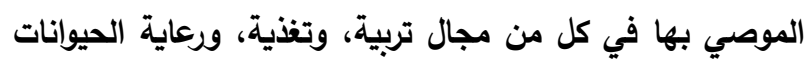

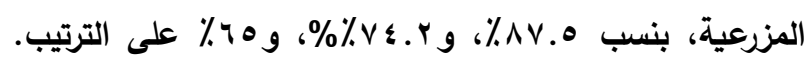

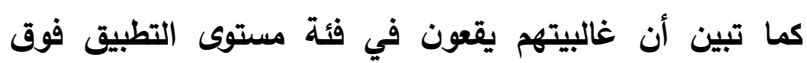

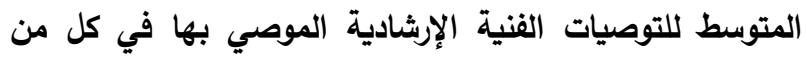

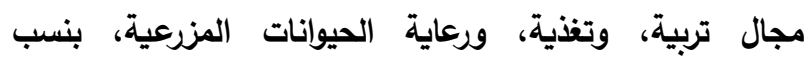

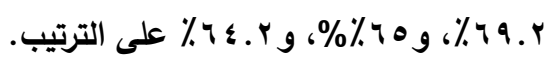

تبين أيضا وجود علاقة طردية معنوية بين درجة تطبيق

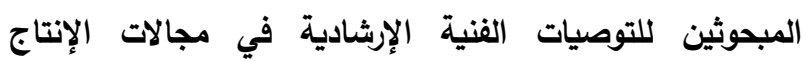
الحيواني الثلاث المدروسة، وبين بعض المتغيرات المستقلة

\section{الملخص العربى}

استهاف هذا البحث تحديد مستوي توافر الذامات المقدمة من الجهات البحثية والإرشادية الززاعية في مجال الإنتاج

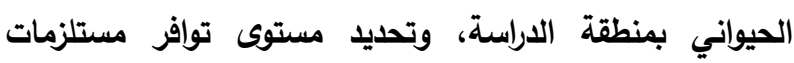
الإنتاج الحيواني، وتحديد معدل تردد المبحوثين على وكلاء التغيير بمنطقة الاراسة، وتحديد مستوى معرفة المبحوثين بالتوصيات الفنية الإرشادية في بعض مجالات الإنتاج الحيواني

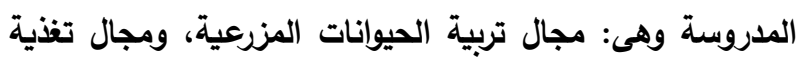
الحيوانات المزرعية، ومجال رعايتها، وتحديد مستوى تطبيق

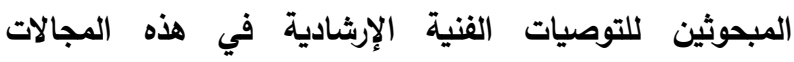
المدروسة، وتحديد معنوية العلاقة بين المتغيرات المستقلة فئنة المدروسة، وبين مستوى تطبيق المبحوثين للتوصيات الفنية

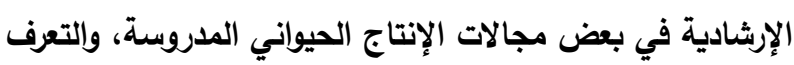
على المشكلات التي تواجه الززاع المبحوثين في مجال الإنتاج الحيواني، ومقترحاتهم للتظلب عليها.

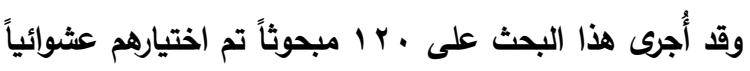

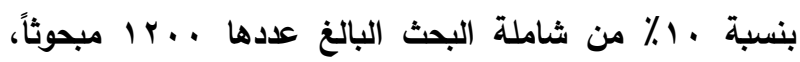
يمثلون عدد الحائزين بقُرى النغناعية، وبراشيم، وكفر عون،

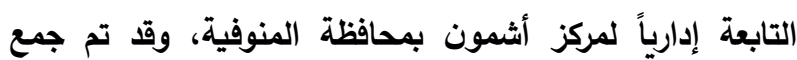

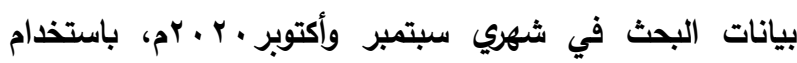

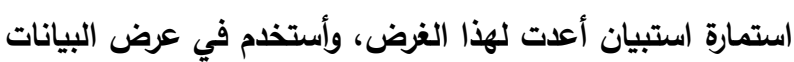

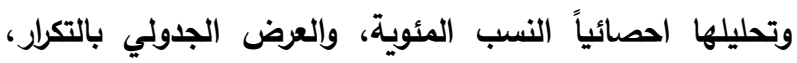

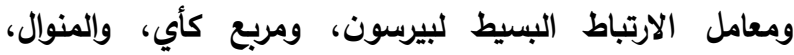
والمتوسط المرجح، وذلك باستخذام برنامج العزم الاحصائية لإنية لإحصائيات العلوم الاجتماعية. SPSS

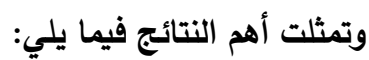




$$
\text { مجلة الإسكندرية للتبادل العلمى - (مجلد ؟ العدد () يناير - مارس (Y.r }
$$

فتتمية الثروة الحيوانية ليست مجرد تتمية للدخل القومي للدولة فحسب، ولكن قد تكون في بعض الأوقات أحد الأسس التي يعتمد عليها الأمن القومي لهذه الدولة. لذا فقد اهتمت الدولة المصرية بتتمية قطاع الثروة الحيوانية لتحقيق إنتاج وطني من اللحوم والألبان يلبي احتياجات السوق المحلية، كما تستهدف بلدعمها لهذا القطاع استكمال الطاقات الإنتاجية بالمزارع، وتدعيم الحملات القومية لتحصين الحيوانات ضد الأمراض، والعمل على تطوير مجازر الإنتاج الحيواني والحجر البيطري لا سيما المحاجر الحدودية، إلى جانب إعداد الدراسات اللازمة

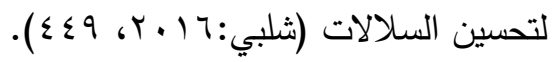
وتمثل الحيوانات المزرعية مورد إنتاج جيد لدى المربى، فهي تمده باللبن والسماد البلدي والعائد النقدي، كما أنها رمز التزيل من رموز المكانة الاجتماعية بين المربين، وكما أنها تعد واليا

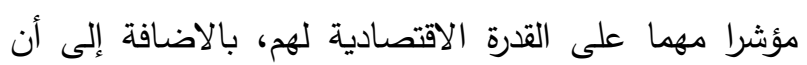
زيادة عدد الحيوانات المزرعية يزيد من المقدرة على استخدام الأساليب التكنولوجية الحديثة وبالأخص أساليب التربية والرعاية السليمة التي تعمل على حفظ وصيانة هذا الرصيد

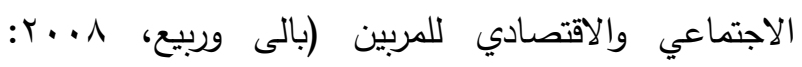
. ( $९$ १९

وتثير دراسة المليجي (Y ( Y :110) إلى أن إنتاج

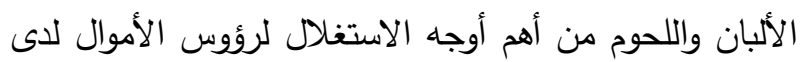
مربى الماشية، ويمثل جزءا كبيرا من دخل المربين، لذا فإن الإممام بطرق تربية وتغذية ورعاية الماشية مع معرفة الطرق الحديثة الموصي بها للحصول على منتجاتها بكفاءة عالية، سيكون ذا أثر كبير في رفع وتحسين الكفاءة الإنتاجية للماشية. وعلى الرغم من ذلك فإن قطاع الإنتاج الحيواني في مصر يواجه مشكلة كبيرة نظرا لعدم العناية بالثروة الحيوانية، حيث يؤدى سوء الرعاية وعدم قدرة المربى على توفير
المدروسة للمبحوثين وهي: عدد سنوات الخبرة في تربية الحيوانات المزرعية، حجم الحيازة الحيوانية، درجة المشاركة في الأنثطة الإرشادية والبيطرية، درجة التعرض لمصادر المعلومات في مجال الإنتاج الحيواني وقد انتهى البحث بمجموعة من التوصيات، والتي قد يفيد تطبيقها في تحسين الانتاج الحيواني بمنطقة الدراسة. الكلمات المفتاحية: المعرفة - التوصيات الارشادية - رعاية الحيوانات المزرعية - الإنتاج الحيواني

\section{المقدمة والمشكلة البحثية}

يعتمد الانسان منذ بدء الخليقة على الحيوانات في سد احتياجاته الضرورية، وفي الدول المتقدمة والنامية على لفى لفي السواء، فان المنتجات الحيوانية هي المكون الرئيسي على مائدة الانسان، هذا بالإضافة إلى مد الانسان بمعظم احتياجاته الأخرى، فلا يمر يوم على الانسان بدون أن لإنى لإنى يستخدم منتج أو أكثر من المنتجات الحيوانية، وفي ظل الل الأزمات سواء كانت هذه الأزمات اقتصادية او صحية، فإن الدول التي تعتمد ذاتيا على انتاج احتياجاتها الغذائية بالذات تكون في مأمن من حدوث كوارث أو مجاعات، وأزمة كرونا خير شاهد على هذا، حيث تعرضت بعض الدول والتي تعتمد على استيراد احتياجاتها الغذائية لأزمات ظهر منها جليا النقص الحاد في بعض المنتجات الغذائية في الأسواق، كما قامت بعض الدور المصدرة من خفض الكميات التي تقوم بتصديرها مخافة استمرار الأزمة، أو شدتها، حيث رأت هذه الدول أنها قد تكون في حاجة لهذه الصادرات لسد احتياجات شعوبها، في حالة إطالة أمد ازمة كرونا. لذلك فان الاهتمام بالإنتاج الذاتي للمواد الغذائية ومنها المنتجات الحيوانية أصبح من الأمور الهامة والملحة لمواجهة آية أزمات قد تكون غير متوقعة، فمهما عظم الدخل القومي لأي دولة بدون مشاركة القطاع الزراعي بثقيه النباتي والحيواني فلن يغنى هذه الدولة ما تمتلكه من وفرة مادية في حال توقف الدول المنتجة للغذاء عن تصديره لها، لذلك 
ولتقليل الفجوة بين حجم العرض والطلب على المنتجات الحيوانية، والذى يرجع في جزء كبير منه إلى تخلف القطاعات الإنتاجية للثروة الحيوانية في مصر، ليس في النقص في أعداد الحيوانات فقط، بل وفي ضعف إنتاجيتها مقارنة بتكاليف الإنتاج، اذا تم مقارنتها بدول على نفس

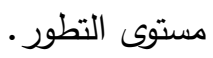

لذا فقد تم اجراء هذا البحث لدراسة مستوى معرفة وتطبيق المزارعين للتوصيات الفنية الموصي بها في مجال الانتاج الحيواني، الأمر الذي يتطلب تعريف الزراع بهذه التوصيات وكيفية تطبيقها بصورة صحيحة، حتى يمكن التغلب على

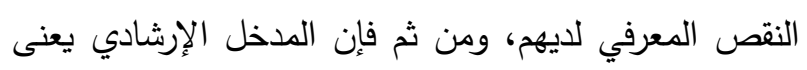
بتقصي مستوى التطبيق بما يخدم صالح التتمية من خلال وضع نتائج هذا البحث أمام متخذي القرار وبالتالي وضعها في الاعتبار عند التخطيط لبرامج إرشادية تتموية في هذا

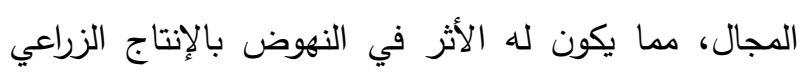

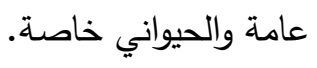

\section{أهداف البحث}

1 - وصف المبحوثين وفقاً للمتغيرات المستقلة المدروسة وهي السن، والحالة التعليمية، عدد سنوات الخبرة في مجال الإنتاج الحيواني، وحجم الحيازة الحيوانية، ودرجة مشاركتهم في الأنشطة الإرشادية الزراعية، وتعرضهم لمصادر المعلومات في مجال الإنتاج الحيواني. r - تحديد مستوى توافر الخدمات المقدمة من الجهات البحثية والإرشادية الزراعية في مجال الإنتاج الحيواني بمنطقة الدراسة.

r - تحديد مستوى توافر مستلزمات الإنتاج الحيواني بمنطقة

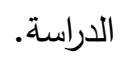

ع - تحديد معدل تردد المبحوثين على وكلاء التغيير وهم: المرشدين الزراعيين، وأخصائي الإنتاج الحيواني، والقادة المحليين، والطبيب البيطري.
مقومات تحسنها إلى انخفاض كفاءتها وإنتاجها (موسى،

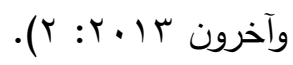
لذلك فان جهاز الارشاد الزراعي له دورا هاما في تتمية وتطوير الانتاج الحيواني من خلال توعية المزارعين بأهمية وخطورة الامراض الحيوانية ورعاية الحيوان من خلال الحملات البيطرية وذلك عبر الوسائل الارشادية المختلفة في مختلف المحافظات مثل الحملات البيطرية الميدانية مع المربين وتوزيع الملصقات والنشرات الإرشادية بالإضافة الى تطبيق عدد من البرامج الزراعية الإذاعية والتليفزيونية عن رعاية الحيوانات المزرعية، وتعتمد الخدمة الارشادية على البرامج التي يترتب عليها تغيير سلوك الزراع أي تتمية معارفهم ومهاراتهم واتجاهاتهم لتحقيق أهداف التتمية الزراعية والمشاركة في تحقيق التتمية الريفية المتكاملة (قشطة،

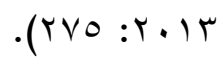
ويعتبر تحديد المستوى المعرفي فيما يتعلق بمجال معين من سياسات ومنهجية العمل الإرشادي، ومن ثم فإن المدخل الذي يعنى بدراسة وتقصى مستوى المعرفة يقدم خدمة جيدة تسهم إسهاما ذا وزن في الكثف عن ذلك المستوى، ومن ثم الارتقاء باه بما يخدم صالح التمية من خلال وضع نتائج الدراسة أمام متخذي القرار، وبالتالي يمكن وضعها في الاعتبار عند التخطيط لبرامج إشادية تتموية (نهى الزاهي

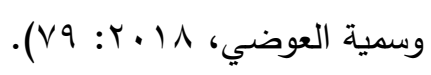

وعليه يتطلب الأمر جهودا مكثفة من الارشاد الزراعى لتعريف المزارعين بالتوصيات الفنية الموصى بها، حيث تقوم فلسفة الارشاد الزراعى على مساعدة الناس على مساعدة أنفسهم فى تغيير سلوكهم فى مواجهة مشكلات حياتهم بهدف احداث التغيرات المطلوبة إقتصاديا وإجتماعيا كنتيجة لهذا التغير السلوكى، ويسعى الارشاد الزراعى لاحداث ذلك من خلال نقل المعارف المستحدثة بين المربين ومساعدتهم على ولى استخدامها بكفاءة للإرتقاع بمستوى الإنتاج (عمر، بول 199 (1): 


$$
\text { مجلة الإسكندرية للتبادل العلمى - (مجلد بـ العدد () يناير - مارس (Y.r }
$$

التابعة إدارياً لمركز أشمون بمحافظة المنوفية، وقد تم جمع بيانات البحث في شهري سبتمبر وأكتوبر · r • rم، باستخدام استمارة استبيان أعدت لهذا الغرض، وذلك وفق منهج المسح الاجتماعي بالعينة، بعد عمل اختبار مبئي لها على عدد 10 حائزاً. وأستخدم في عرض البيانات وتحليلها احصائياً النسب المئوية، والعرض الجدولي بالتكرار، ومعامل الارتباط

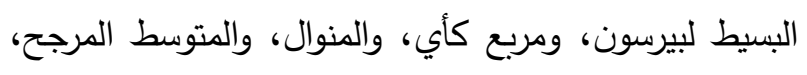
وذلك باستخدام برنامج الحزم الاحصائية لإحصائيات العلوم

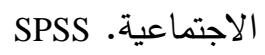

جدول ا ـ بيان بشاملة وعينة الدراسة في الجمعيات التعاونية الزراعية بالقرى المختارة

\begin{tabular}{|c|c|c|c|}
\hline \multirow{2}{*}{ حجم العينة } & الشاملة * الشا & \multirow{2}{*}{ المختارة } & \multirow[b]{2}{*}{ r } \\
\hline & عدد الحائزين بها & & \\
\hline 0. & $0 .$. & النعناعية & 1 \\
\hline$\varepsilon V$ & $\varepsilon V$. & براشيم & $r$ \\
\hline r & r. & كفر عون & r \\
\hline $1 \%$. & Ir.. & الإجمالي & $<$ \\
\hline
\end{tabular}

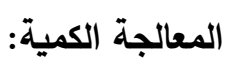
أولاً: المتغيرات المستقلة المدروسة للمبحوثين. السن: وتم قياسه بعدد سنوات عمر المبحوث وقت جمع البيانات كرقم خام مقرباً لأقرب سنة ميلادية، وقد بلغ المدي ليدوات الفعلي لسن المبحوثين سم سنة بحد أدنى هب سنة، وحد أقصى VT سنة، وقد تم توزيع المبحوثين على ثلاث فئات

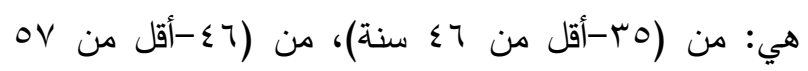
سنة). من (OV سنة فأكثر ). الحالة التعليمية: تم قياسها بسؤال المبحوثين عن الحالة التعليمية وقت الاستبيان، وتم تقسيم المبحوثين وفقاً لحالتهم التعليمية إلى اربع فئات هي: أمي، ويقرأ ويكتب، ومؤهل

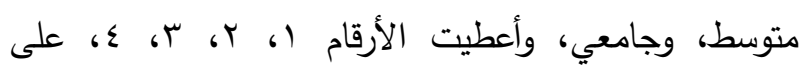

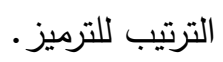

0 - تحديد مستوى معرفة المبحوثين بالتوصيات الفنية الإرشادية في بعض مجالات الإنتاج الحيواني المدروسة وهي: مجال تربية الحيوانات المزرعية، ومجال تغذية لإنتادية الحيوانات المزرعية، ومجال رعايتها. 7 الإرشادية في بعض مجالات الإنتاج الحيواني المدروسة. - V للمبحوثين وهى: السن، والحالة التعليمية، وعدد سنوات الخبرة في تربية الحيوانات المزرعية، وحجم الحيازة الحيوانية. ودرجة مشاركتهم في الأنشطة الإرشادية الزراعية، ودرجة تعرضهم لمصادر المعلومات في مجال الإنتاج الحيواني، وبين مستوى تطبيقهم للتوصيات الفنية

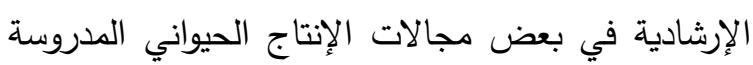
وهى: مجال تربية الحيوانات المزرعية، ومجال تغذية الحيوانات المزرعية، ومجال رعايتها. ᄉ - التعرف على المشكلات التي تواجه الزراع المبحوثين في مجال الإنتاج الحيواني، ومقترحاتهم للتغلب عليها.

\section{الفرض البحثي}

توجد علاقة معنوية بين المتغيرات المستقلة المدروسة للمبحوثين وهي: السن، والحالة التعليمية، وعدد سنوات الخبرة في تربية الحيوانات المزرعية، وحجم الحيازة الحيوانية. ودرجة مشاركتهم في الأنشطة الإرشادية الزراعية، ودرجة تعرضهم لمصادر المعلومات في مجال الإنتاج الحيواني، وبين مستوي تطبيقهم للتوصيات الفنية الإرشادية في بعض مجالات الإنات الإنتاج الحيواني المدروسة. وتم اختباره في صورته الصفرية بوضع كلمة (لا) في بدايته.

\section{الطربقة البحثية}

أُجرى هذا البحث على . با مبحوثاً تم اختيارهم عشوائياً بنسبة . 1\% من شاملة البحث البالغ عددها . . Y ا مبحوثاً،

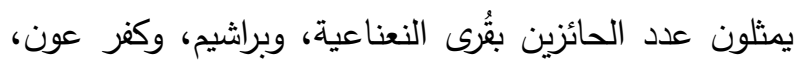


المبحوثين وفقاً لحجم حيازتهم الحيوانية مقدرة بالوحدات

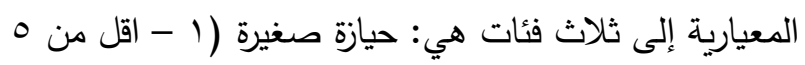

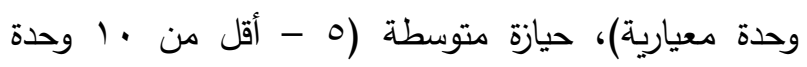
معيارية)، حيازة كبيرة (· ( وحدة معيارية فأكثر) ).

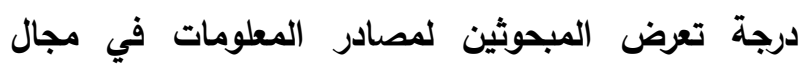

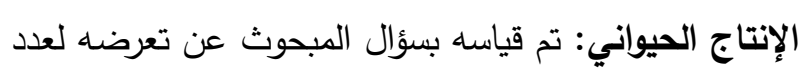

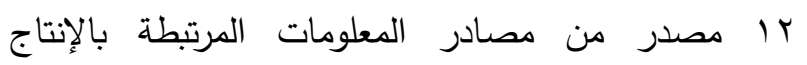
الحيواني وهى: المرشدين الزراعيين، والطبيب البيطري، وكبار

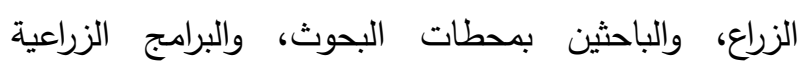

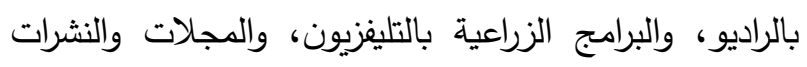

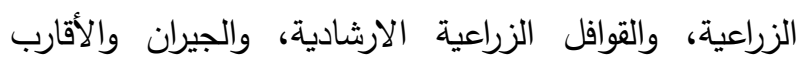

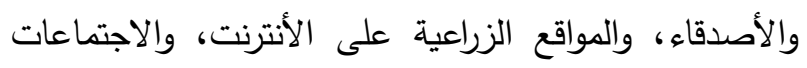
والندوات الإرشادية، ومسئولي الاتتاج الحيواني بالمحافظة الأنية وذلك على مقياس ثلاثي هو : دائماً، وأحياناً، ونادراً، وأعطيت الأني

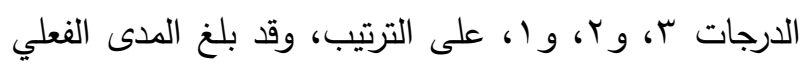
لارجة تعرض المبحوثين للصادر المعلومات آب درجة، بحد

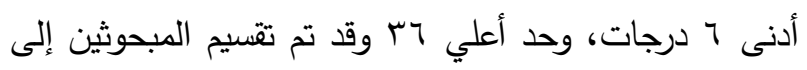

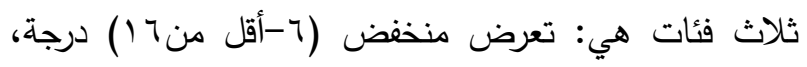

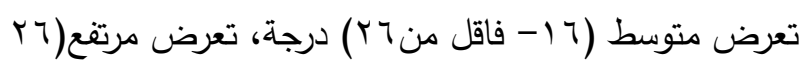
درجة فأكثر ).

ثانياً: مستوي توافر الذدمات المقدمة من الجهات البحثية

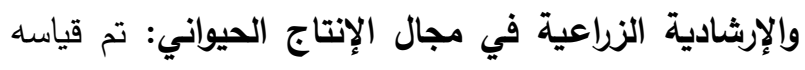

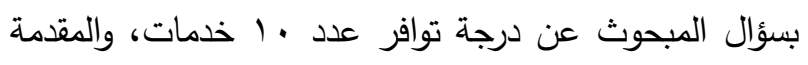

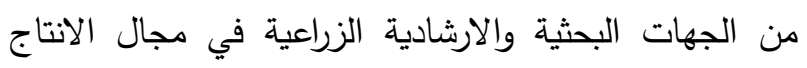
الحيواني، وذلك على مقياس ثلاثي: درجة كبيرة، درجة

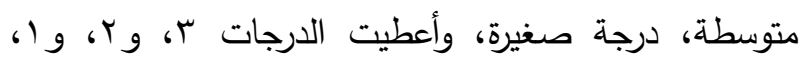

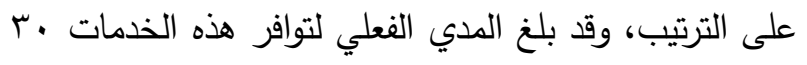

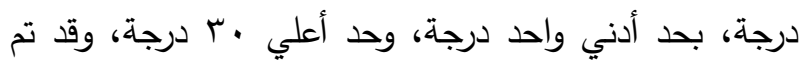
تقسيم المبحوثين وفقاً لرأيهم في درجة توافر هذه الخدمات

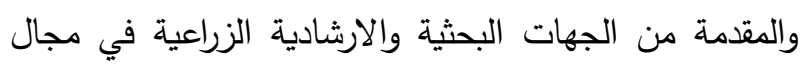
الانتاج الحيواني إلى ثلاث مستويات وهي: متوفرة بدرجة
عدد سنوات الخبرة في تربية الحيوانات المزرعية: تم قياسها بسؤال المبحوث عن عدد سنوات خبرته في مجال تربية

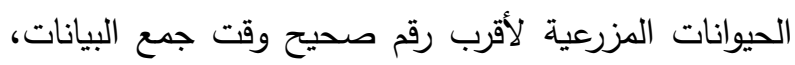
وتم التعبير عنه كرقم خام، وقد بلغ الددي الفعلي لعدد

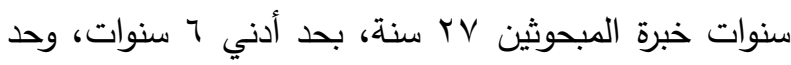

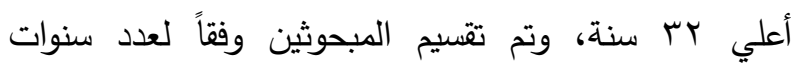
خبرتهم في تربية الحيوانات المزرعية إلى ثلاث فئات هي:

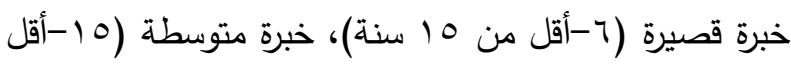

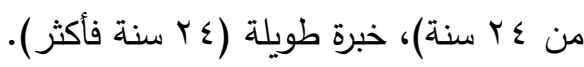
درجة المشاركة في الأنثطة الإرشادية: تم قياسها بسؤال

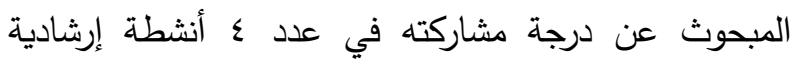

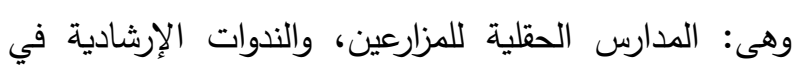

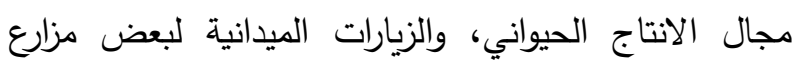

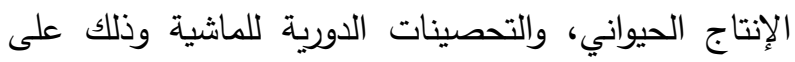

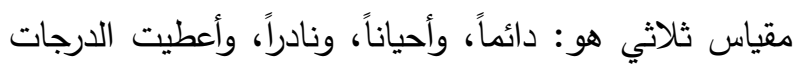

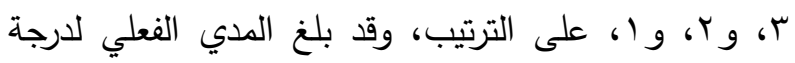

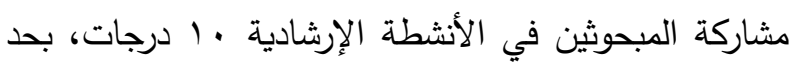

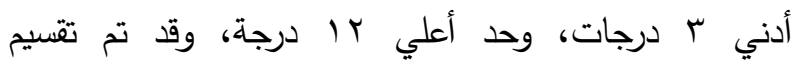
المبحوثين وفقاً لارجة مشاركتهم في الأنثطة الإرشادية إلى وحلى ثلاث فئات هي: مشاركة منخفضة (T - أقل من 1 د درجات) ، مشاركة متوسطة (ף- أقل من 9 درجات)، مشاركة مرتغعة (9 درجات فأكثر) ) حجم الحيازة الحيوانية: تم قياسه بسؤال المبحوث عن عدد الحيوانات المزرعية التي تقوم أسرته المعيشية بتربيتها وقت

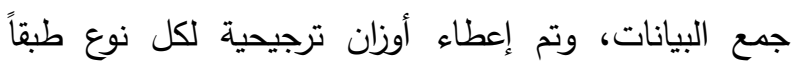
لنموذج البنك الدولي للوحدات الحيوانية بحيث يعطى للإبل إنل

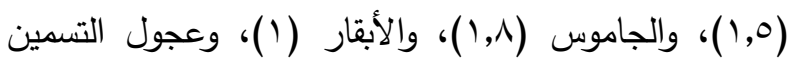

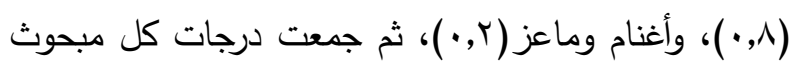

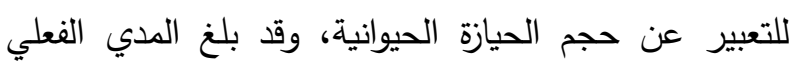

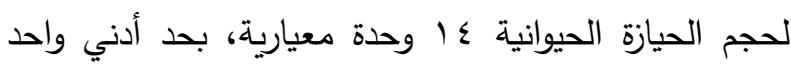
وحدة معيارية، وحد أعلى عا وحدة معيارية، وتم تقسيم 
مستوي معرفة المبحوثين بالتوصيات الفنية الإرشادية في مجال تربية الحيوانات المزرعية: تم قياسه بسؤال المبحوث المبوث

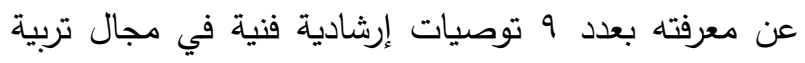

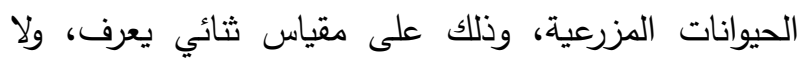

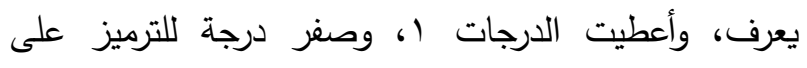

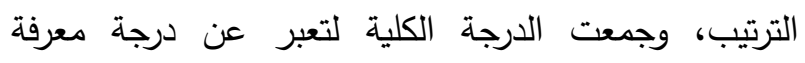
المبحوث بهذه التوصيات، وقد بلغ الددي الفعلي لدرجة معرفة

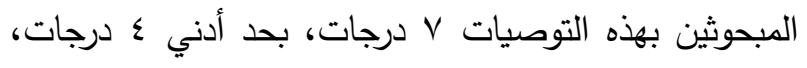

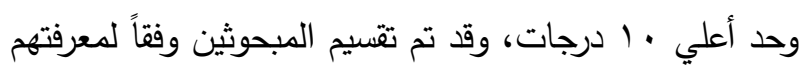

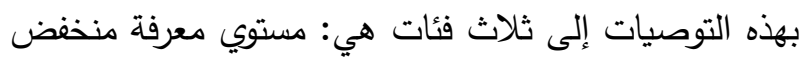

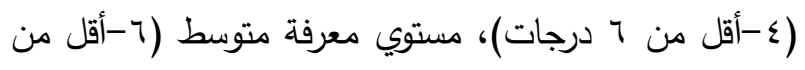
^ درجات)، مستوي معرفة مرتفع (^ درجات فأكثر). مستوي معرفة المبحوثين بالتوصيات الفنية الإرشادية في مجال تغذية الحيوانات المزرعية: تم قياسه بسؤال المبحوث

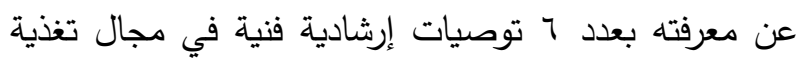

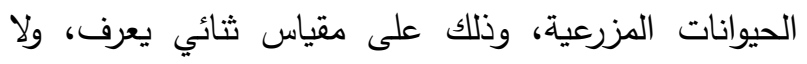

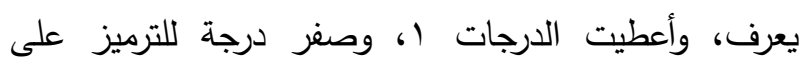
الترتيب، وجمعت الدرجة الكلية لتعبر عن درجة معرفة

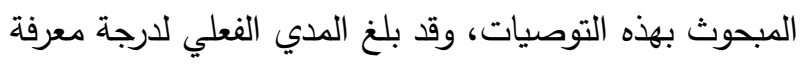

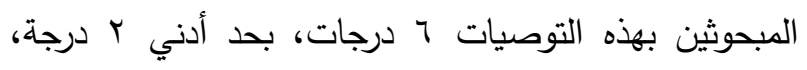
وحد أعلي V درجات، وقد تم تقسيم المبحوثين وفقاً لمعرفتهر

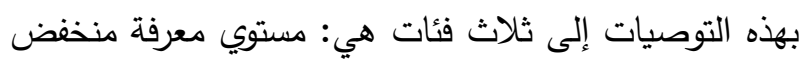

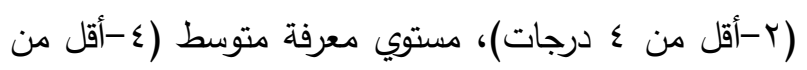
† درجات)، مستوي معرفة مرتفع († درجات فأكثر). مستوي معرفة المبحوثين بالتوصيات الفنية الإرشادية في داتئي

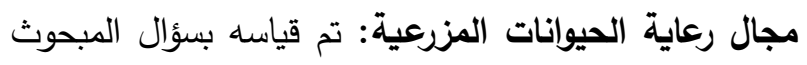
عن معرفته بعدد • ا توصيات إرشادية فنية في مجال رعاية

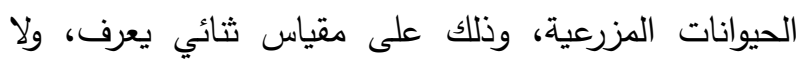

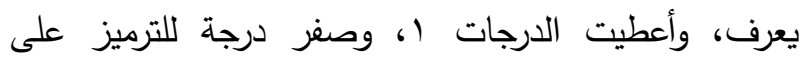

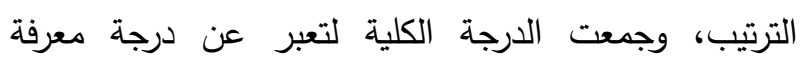
المبحوث بهذه التوصيات، وقد بلغ الددي الفعلي لدرجة معرفة لدنة
منخفضة (ا-أقل من ·1 درجة)، متوفرة بدرجة متوسطة

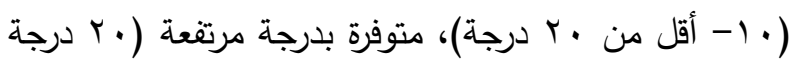
فأكثر ).

ثُالثاً: مستوي توافر مستلزمات الإنتاج الحيواني: تم قياسه بسؤال المبحوث عن رأيه في توفر كل من: السلالات

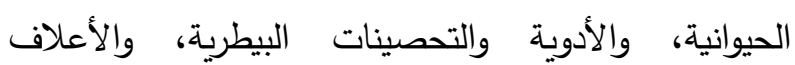
الخضراء والمركزة، ومعدات تصنيع الكمبوست، وأدوات

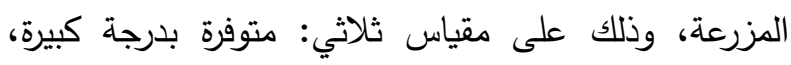

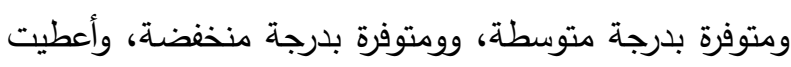
الدرجات rا، و r، و ا، على الترتيب، وقد بلغ الددي الفعلي

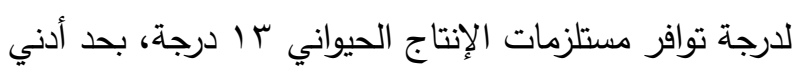

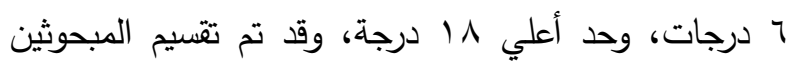
وفقاً لرأيهم في درجة توافر مستلزمات الانتاج الحيواني إلى داتى

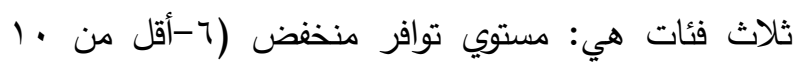

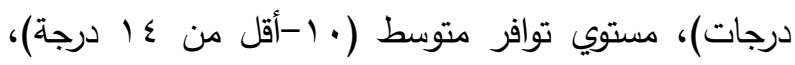
مستوي توافر مرتفع (ع ا درجة فأكثر) . رابعاً: التردد على وكلاء التغيير: تم قياسه بسؤال المبحوث

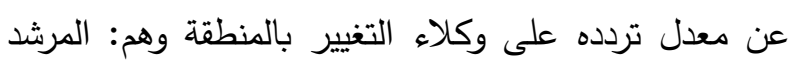

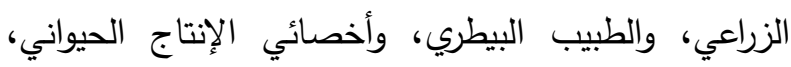

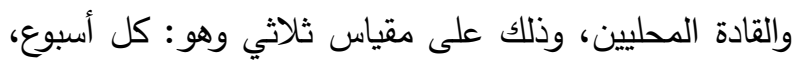

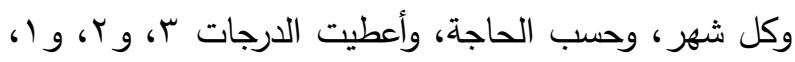
على الترتيب. وقد بلغ الددي الفعلي لـعدل تردد المبحوثين

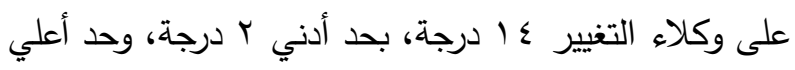
10 درجة، وقد تم توزيع المبحوثين على ثلاث فئات، وهي:

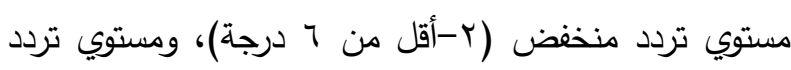

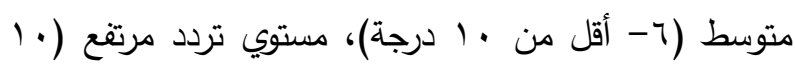

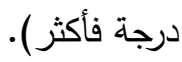
خامساً: مستوي معرفة المبحوثين بالتوصيات الفنية الإرشادية في بعض مجالات الإنتاج الحيواني وهي: مجالئ التوصيات الفية

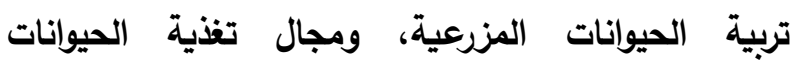
المزرعية، ومجال رعايتها. 
أقل من Y I درجة)، مستوي تطبيق متوسط (Y ا-أقل من V V )، مستوي تطبيق مرتفع (V V درجة فأكثر). مستوي تطبيق المبحوثين للتوصيات الفنية الإرشادية في

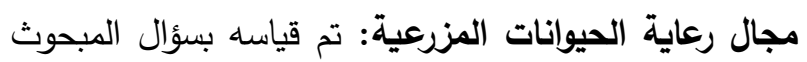
عن تطبيقه لعدد ·1 توصيات إرشادية فنية في مجال رعاية

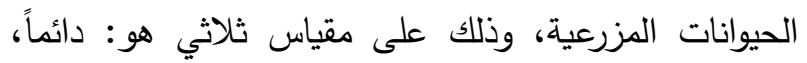

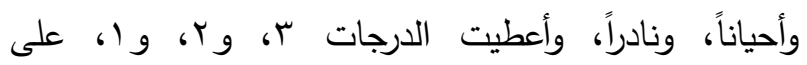
الترتيب، وقد بلغ المدي الفعلي لدرجة تطبيق المبحوثين لهذه

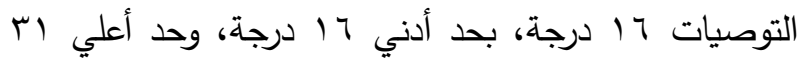

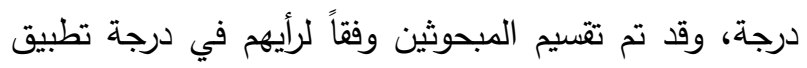
التوصيات الفنية الإرشادية في مجال رعاية الحيوانات المزرعية إلى ثلاث فئات هي: مستوي تطبيق منخفض الآناه

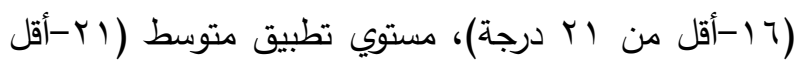

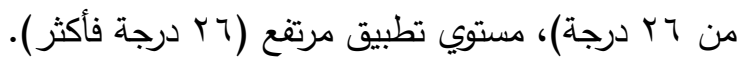

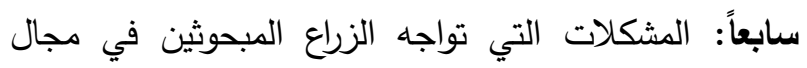

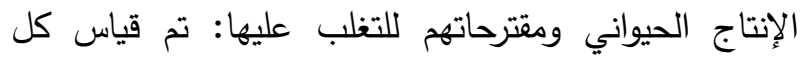
منهما بتوجيه سؤال مفتوح للمبحوث عن الششكلات التي تواجهه أثناء تربية، وتغذية، ورعاية الحيوانات المزرعية، ومقترحاته للتغلب عليها، ثم تجميع الآراء المتثابه حول كل من المشكلات، ومقترحاتهم لمواجهتها، وتم حصرها بالتكرارات

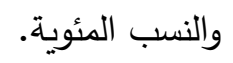

\section{النتائج ومناقشتها}

أولاً: المتغيرات المستقلة المدروسة للمبحوثين:

تثثير النتائج الواردة بجدول رقم (Y) إلى أن المتغيرات

الثخصية للمبحوثين جاءت كالتالي:

السن: منوال سن المبحوثين جاء في الفئة السنية (هب-أقل من 7؟ سنة) وبلغت نسبتهم V. العمر ويكون فيها الانسان لديه القدرة على بذل مجهود أكبر الحالة التعليمية: ما يزيد عن نصف المبحوثين (1.؛ـ\%)

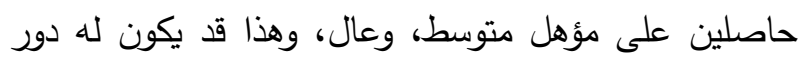

المبحوثين بهذه التوصيات V درجات، بحد أدني ؛ درجات،

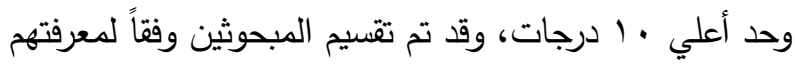
بهذه التوصيات إلى ثلاث فئات هي: مستوي معرفة منخفض

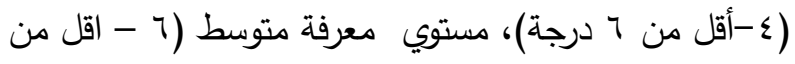
^ درجات)، مستوي معرفة مرتفع (^ درجات فأكثر ). سادساً: مستوي تطبيق المبحوثين للتوصيات الفنية

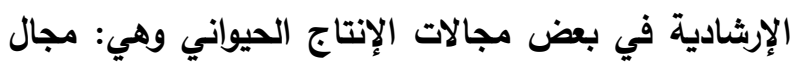
تربية الحيوانات المزرعية، ومجال التغذية، ومجال الرعاية. مستوي تطبيق المبحوثين للتوصيات الفنية الإرشادية في

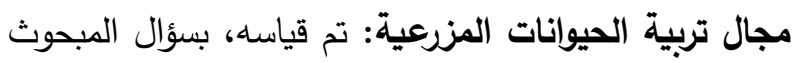

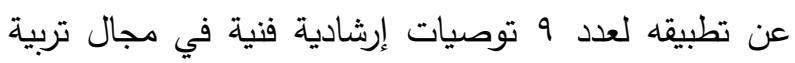
الحيوانات المزرعية، وذلك على مقياس ثلاثي هو : دائماً،

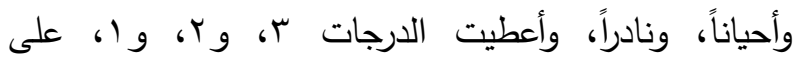

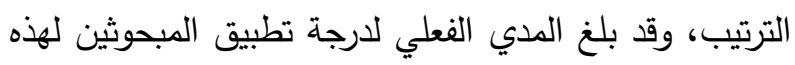

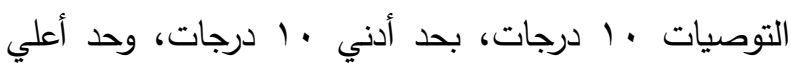

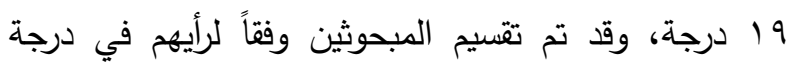
تطبيق التوصيات الفنية الإرشادية في مجال تربية الحيوانات المزرعية إلى ثلاث فئات هي: مستوي تطبيق منخفض

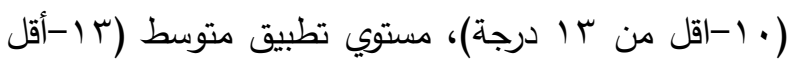
من 17 درجة)، مستوي تطبيق مرتفع (7 ادرجة فأكثر). مستوي تطبيق المبحوثين للتوصيات الفنية الإرشادية في

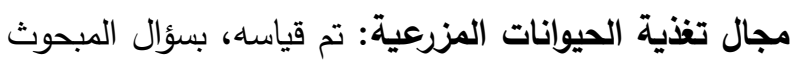
عن تطبيقه لعدد 1 توصيات إرشادية فنية في مجال تغذية الحيوانات المزرعية، وذلك على مقياس ثلاثي هو: دائماً،

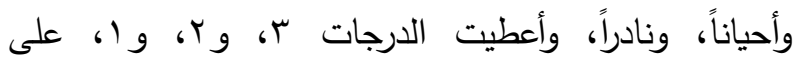
الترتيب، وقد بلغ المدي الفعلي لدرجة تطبيق المبحوثين لهذه

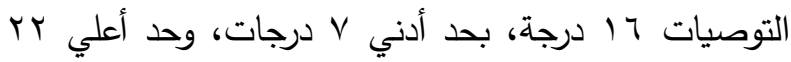
درجة، وقد تم تقسيم المبحوثين وفقاً لرائيهم في درجة تطبيق التوصيات الفنية الإرشادية في مجال تغذية الحيوانات المزرعية إلى ثلاث فئات هي: مستوي تطبيق منخفض الإتاديه في لغيال 
الخاطئ لمبادئ الثريعة الإسلامية، في مسالة المواريث،

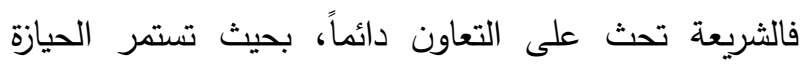

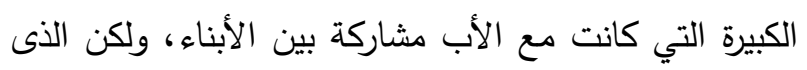

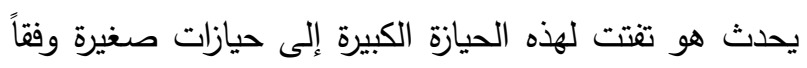

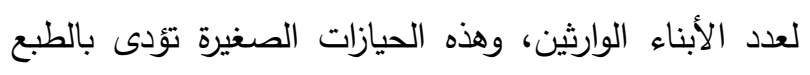

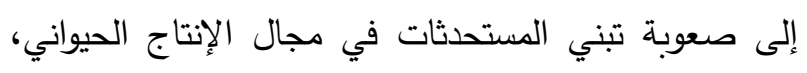

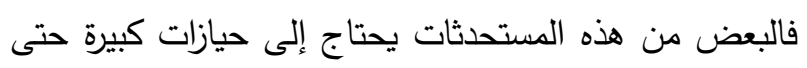
يتناسب مع تكلفة المستحدث.

التعرض لمصادر المطلومات: ما يقرب من ثلاث ارباع

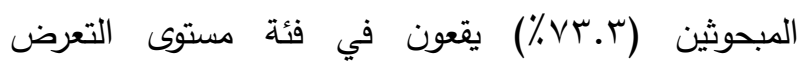

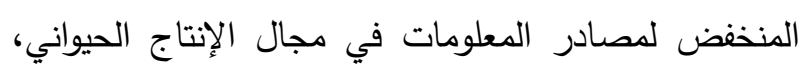
وقد يرجع السبب على ذلك إلى صغر حجم الحيازة الحيوانية

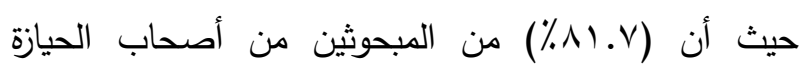
الصغيرة، والحيازات الصغيرة تؤدى إلى عدم الهتمام حائزيها بالاطلاع على ومتابعة الحديث من توصيات الانتاج

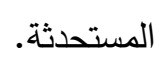

كبير في سرعة استيعابهم للمستحدثات، وتعرفهم على التى التوصيات الخاصة بمجال الإنتاج الحيواني. سنوات الخبرة: أن ما يزيد عن ثلثي المبحوثين (T.0.

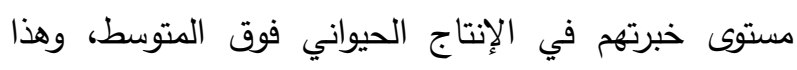

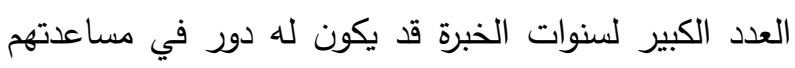
على تطبيق التوصيات الخاصة بتربية، وتغذية، ورعاية الحيوانات المزرعية بحكم مرورهم بتجارب عديدة خلال

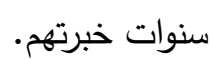
المشاركة في الأنثطة الإرشادية: ما يقرب من ثلاثة أرباع

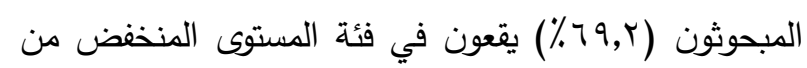

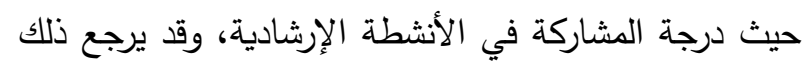
إلى قلة هذه الأنشطة بسبب تناقص عدد المرشدين الزراعيين،

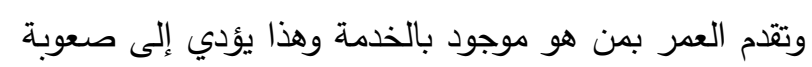
تأقلمه مع المستحدثات. حجم الحيازة الحيوانية: أن الغالبية العظمي من المبحوثين

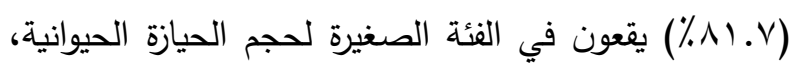
وهذا يتماشى مع التفتت الحيازي، بسبب الفهم والتطبيق

جدول r ـ التوزيع العددي والنسبي للمبحوثين وفقاً للمتغيرات الثخصية المدروسة

\begin{tabular}{|c|c|c|c|c|c|}
\hline$\%$ & العدد & 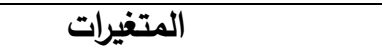 & $\%$ & العدد & المتغيرات \\
\hline \multicolumn{3}{|c|}{ درجة المشاركةّ فى الأنثطة الإرشادية (درجة) } & \multicolumn{3}{|c|}{ السن (سنة) } \\
\hline 79.4 & ז" & منخفضة (r- آقل من ؟) & \multicolumn{3}{|c|}{ السن (سنة) } \\
\hline 19.4 & r & متوسطة (1 - أقل من 9) & rq.1 & $\leqslant v$ & TY - أقل من OV \\
\hline 11.7 & ir & مرتفعة (9 فأكثر) & 9.Y & 11 & ov \\
\hline $1 \ldots$ & ir. & الإجمالى & $1 \ldots$ & IT. & \\
\hline \multicolumn{3}{|c|}{ حجم الحيازة آلحيوانية (وحدة معياربة) } & \multicolumn{3}{|c|}{ الحالة التعليمية } \\
\hline & & & Q.Y & 11 & \\
\hline$\Lambda 1 . V$ & 91 & صغيرة (1 فاقل من 0) & r.. & $\varepsilon \varepsilon$ & ل يقراً ويكتب \\
\hline IT.r & 17 & متوسطة (0 فاقل · 1) & ץ.. & Tr & مؤهل متوسط \\
\hline 。 & 7 & كبيرة (· أ فأكثر) & rV.O & זس & \\
\hline $1 \ldots$ & ir. & 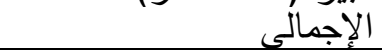 & $1 \ldots$ & ir. & الإجمالى \\
\hline \multicolumn{3}{|c|}{ درجة التعرض لمصادر المعلومات (درجة) } & \multicolumn{3}{|c|}{ عدد سنوات الخبرة فى الإنتاج الحيوانى (سنة) } \\
\hline$V T . r$ & $\Lambda \Lambda$ & منخفضة (7 فاقل من 7 (1) & rT.O & rq & قصيرة : 7 فاقل من 10 \\
\hline$r \Sigma . r$ & rq & 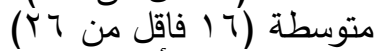 & $\varepsilon r . \Gamma$ & or & متوسطة: 10 فاقل من ؟Y \\
\hline r.O & $r$ & مرتفعة (ج فأكثر) & $r \varepsilon . r$ & rq & طويلة : : ب فأكثر \\
\hline $1 \ldots$ & ir. & 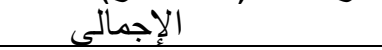 & $1 \ldots$ & IT. & 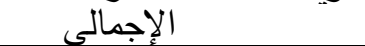 \\
\hline
\end{tabular}


وفي المرتبة الثامنة جاءت خدمة توفر لقاءات إرشادية

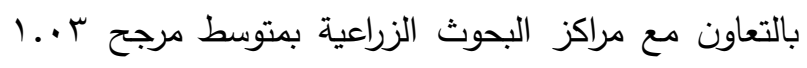
درجة. وفي المرتبة التاسعة والأخيرة جاءت خدمة توفر تقديم النصح والإرشاد لهربى الثروة الحيوانية، بمتوسط مرجح

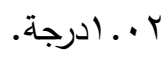

وقد بلغ المتوسط المرجح الإجمالي لارجة توافر الخدمات المقدمة من الجهات البحثية والإرشادية الزراعية في مجال

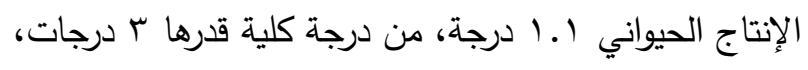
وهو ما يشير إلى ضعف هذه الخدمات بشكل ظاهر وملموس، وقد يرجع السبب إلى تتاقص عدد المرشدين الزراعيين بشكل خاص، والعاملين في مجال الارشاد الزراعي بشكل عام لعدم تعويض الفاقد منهم بسبب الخروج إلى المعاش أو الوفاة، مما أدى إلى تتاقص متزايد في القائمين

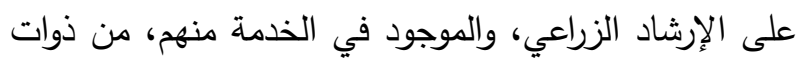
الأعمار المرتقعة، بحيث يصل متوسط أعمارهم فوق الخمسة والخمسون عاماً، وهذا في عرف العمل الحكومي استعداد للخروج على المعاش، ويريد إتمام الباقي من سنوات خدمته

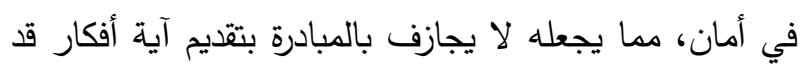

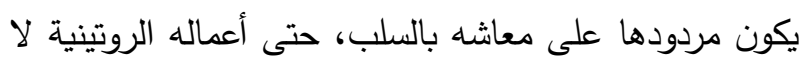
يهتم بتنفيذها.
ثانياً: درجة توافر الخدمات المقدمة من الجهات البحثية والإرشادية الزراعية في مجال الإنتاج الحيواني: لونيات تثير النتائج الواردة بجدول رقم (ب) إلى أن المتوسط

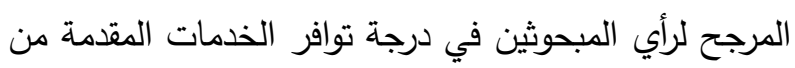
الجهات البحثية والإرشادية الزراعية في مجال الإنتاج

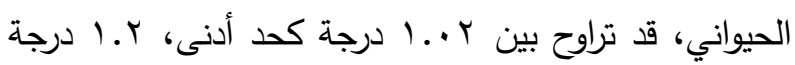

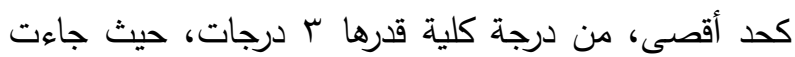
خدمة توفر البرامج الوقائية الإششادية بالتعاون مع الطب دانب البيطري، في المرتبة الأولى، بمتوسط مرجح ب.ا الإنجة درجة، يليها في المرتبة الثانية، توفر البرامج الإرشادية من خلال المراكز الإرشادية حول الثروة الحيوانية، بمتوسط مرجح 10 ـ ا درجة، وفي المرتبة الثالثة جاءت خدمة توفر اللقاءات الإرشادية في الإدارات الزراعية حول الجديد في الثروة

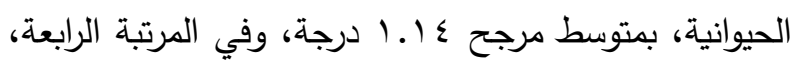
جاءت خدمة توفر القوافل الزراعية لكليات الزراعة حول الإنتاج الحيواني، بمتوسط مرجح 1 (. 1 درجة، وفي المرتبة الخامسة، جاءت خدمة توفر الندوات والاجتماعات الإرشادية حول الإنتاج الحيواني، بمتوسط مرجح • (1 درجة، وفي المرتبة السادسة جاءت خدمة توفر الدورات الإرشادية حول هولئ كيفية عمل السيلاج والدري، بمتوسط مرجح 9 . ـ. درجة، وفي المرتبة السابعة جاءت خدمة توفر لقاءات إرشادية حول كيفية وتطبيق التلقيح الصناعي بمتوسط مرجح 7 . ـ ا درجة، 
جدول r. توزيع المبحوثين وفقاً لرأيهم في درجة توافر الذدمات المقدمة من الجهات البحثية والإرشادية الزراعية في مجال الإنتاج الحيواني

\begin{tabular}{|c|c|c|c|c|c|c|}
\hline \multirow[b]{2}{*}{ 膤 } & \multirow[b]{2}{*}{ 尔 } & \multicolumn{3}{|c|}{ درجة التوافر } & \multirow[b]{2}{*}{ الخدمات البحثية والإرشادية الزياعية في } & \multirow[b]{2}{*}{ r } \\
\hline & & :\$ & శู & 佂 & & \\
\hline 1 & $1 . Y \cdot$ & 97 & Yร & $\cdot$ & برامج وقائية إرشادية بالتعاون مع الطب البيطري & 1 \\
\hline r & 1.10 & $1 \cdot 1$ & 19 & . & برامج إرشادية من خلال المراكز الإرشادية حول الثروة الحيوانية & r \\
\hline r & $1.1 \leq$ & $1 \cdot r$ & iv & . & لقاءات إرشادية في الإدارات الزراعية حول الجديد في الثروة الحيوانية & $r$ \\
\hline$\varepsilon$ & 1.11 & 1.7 & $1 \leq$ & . & قوافل زراعية لكليات الزراعة حول الإنتاج الحيواني " ق & $\varepsilon$ \\
\hline 0 & 1.1. & $1 \cdot v$ & M & . & ندوات واجتماعات إرشادية حول الإنتاج الحيواني & • \\
\hline 1 & $1 . .9$ & 1.9 & 11 & - & دورات إرشادية حول كيفية عمل السيّلآج والدريس & 9 \\
\hline$V$ & $1 .+7$ & 114 & $\wedge$ & . & لقاءات إرشادية حول كيفية وتطبيق التلقيح الصناعي & v \\
\hline$\wedge$ & $1 . . r$ & 111 & r & . & لقاءات إرشادية بالتعاون مع مراكز البحوث الزراعية & $\wedge$ \\
\hline$\wedge$ & $1 . . r$ & 119 & r & . & تقديم النصح والإرشاد لمربي الثروة الحيوانية. & 9 \\
\hline & 1.1 & & & & المتوسط المرجح الاجمالى & \\
\hline
\end{tabular}

ثالثاً: درجة توافر مستلزمات الإنتاج الحيواني: تثير النتائج الواردة بجدول رقم (0) إلى أن المتوسط

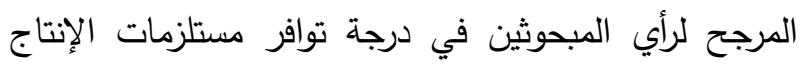

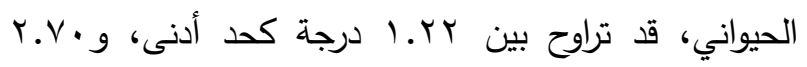

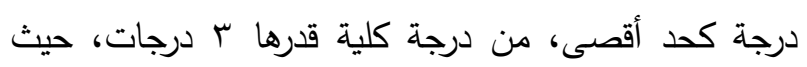

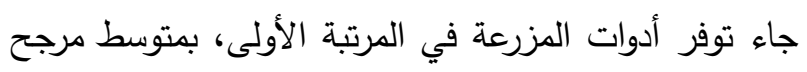

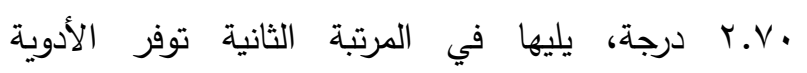

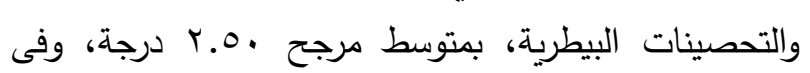

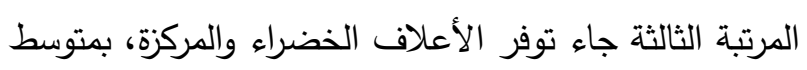

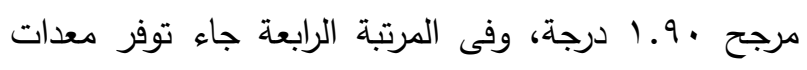

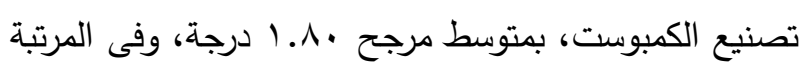

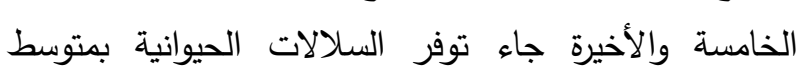
مرجح r ب.ا درجة. وقد بلغ المتوسط المرجح الاجمالي ب ب. بـ درجة، وهو

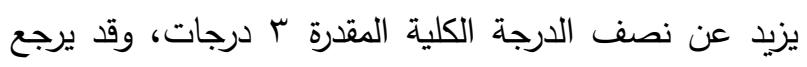

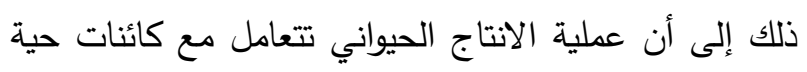

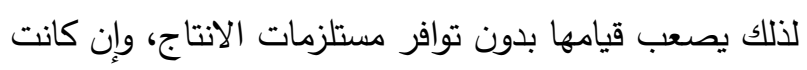
بعض المستلزمات تتوافر أكثر من البعض الآخر ، كالأدوات
وبتوزيع المبحوثين على فئات وفقاً لرأيهم في درجة توافر

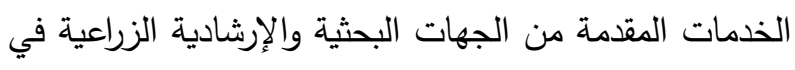

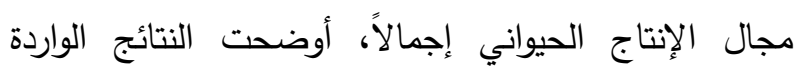

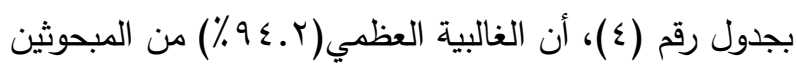

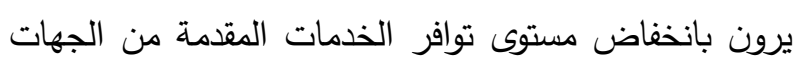

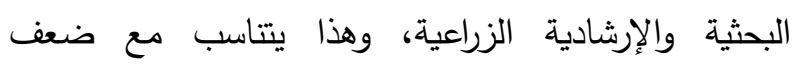

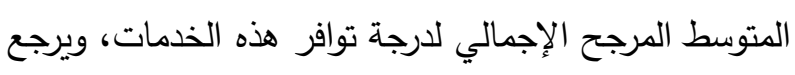

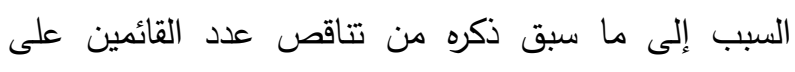
العمل الإرشادي الزراعي، وحتي في حالة توافر الخدمات

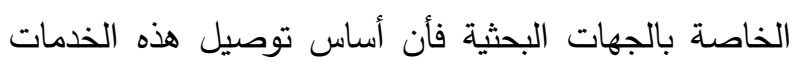
هم المرشدين الزراعيين. جدول ؛. توزيع المبحوثين وفقاً لرأيهم في درجة توافر الزئ الذدمات المقدمة من الجهات البحثية والإرشادية الزراعية

\begin{tabular}{|c|c|c|c|}
\hline & \multicolumn{3}{|c|}{ في مجال الإنتاج الحيواني إجمالاً } \\
\hline$\%$ & عدد & مسنتوى التوافر (درجة) & 5 \\
\hline $9 \varepsilon, Y$ & $11 \pi$ & منخفض (1 _اقل من • () & $T$ \\
\hline 0,1 & $\mathrm{v}$ & متوسط( • ( ـاقل من • ץ) & r \\
\hline . & - & مرتفع (•• فأكثر) & r \\
\hline $1 \ldots$ & Tr. & الإجمالي & \\
\hline
\end{tabular}


المرتبة الثانية الطبيب البيطري، بمتوسط مرجح بr. ا درجة، وفى المرتبة الثالثة جاء المرشد الزراعي، بمتوسط مرجح

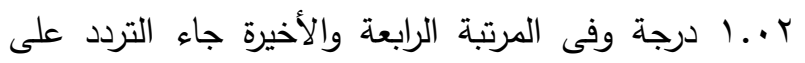

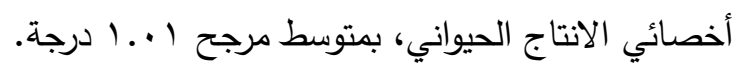
وقد بلغ المتوسط المرجح الاجمالي ع ــا د درجة من درجة كلية قدرها ب درجات، في حين بلغ المتوسط المرجح لتردد المبحوثين على المرشد الزراعي كأحد أهم وكلاء التغيير r +. ادرجة وهو ما يعكس ضعف هذا التردد بصورة واضحة، وهو ما قد يرتبط بتأكل وتتاقص أعداد المرشدين الزراعيين بشكل عام نتيجة لعدم تعويض الفاقد منهم سواء بالخروج

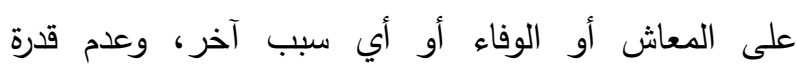

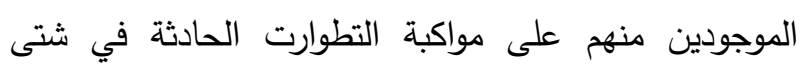
مجالات الانتاج الزراعي، بثقية النباتي والحيواني، وقد يرجع ذلك إلى تقدمه في العمر، حيث أنه حسب توقف تعيين المرشدين الزراعيين فإن متوسط أعمار الموجودين منهم

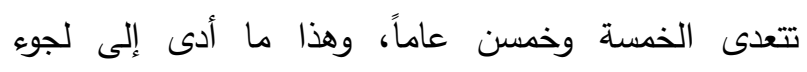
المبحوثين إلى القادة المحليين كمصدر للمعلومات خاصة وحنة عند الحاجة، واللجوء إلى الطبيب البيطري في الأمور الملحة.
الزراعية، والأدوية والتحصينات البيطرية التي جاءت بمتوسط مرجح يزيد عن المتوسط العام، ويقترب من الدرجة الكلية، في حين أن بعض المستلزمات جاءت اقل من المتوسط العام، قد يكون هذا مؤشر يهتىى به المسئولين للاهتمام بمعالجة أوجه القصور في بعض مستلزمات الانتاج الحيواني. وبتوزيع المبحوثين وفقاً لرأيهم في درجة توافر مستلزمات الإنتاج الحيواني، أوضحت النتائج الواردة بجدول رقم (T) أن ما يزيد عن خمسي المبحوثين (بـ٪) يقعون في المستوي المرتفع ممن يرون بتوافر مستلزمات الإنتاج الحيواني، وتعكس النتائج السابقة توفر مستلزمات الإنتاج الحيواني المدروسة بدرجة متوسطة بمنطقة الدراسة. رابعاً: التردد على وكلاء التغيير: تشير النتائج الواردة بجدول رقم (V) إلى أن المتوسط المرجح لدرجة تردد المبحوثين على وكلاء التغيير ، قد تراوح

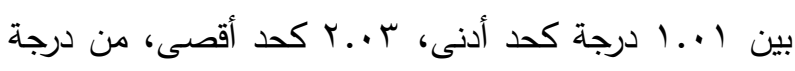
كلية قدرها ب درجات، حيث جاء التردد على القادة المحليين في المرتبة الأولي، بمتوسط درجح ب. •r درجة، يليهم في

\begin{tabular}{|c|c|c|c|c|c|c|}
\hline \multirow[b]{2}{*}{ الترتيب } & \multirow{2}{*}{ المتوسط } & \multicolumn{3}{|c|}{ درجة التوافّر } & \multirow{2}{*}{ مستلزمات الإنتاج الحيواني المدروسة } & \multirow[b]{2}{*}{ ? } \\
\hline & & صغيرة & متوسطة & كبيرة & & \\
\hline 1 & Y.V. & 9 & 11 & 94 & آدوات المزرعة & 1 \\
\hline r & T.O. & ir & ro & $v r$ & الأَوية والتحصينات البيطرية & r \\
\hline r & 1.9 & r. & $\vee \cdot$ & $r$. & الأعلاف الخضراء والمركزة & $r$ \\
\hline$\varepsilon$ & 1.1. & ov & rq & rs & معدات تصنيع الكمبوست & $\varepsilon$ \\
\hline 0 & $1 . r T$ & $r v$ & $\varepsilon r$ & ir & السلالات الحيوانية & 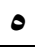 \\
\hline & Y.. Y & & & & المتوسط المرجح الاجمالى & \\
\hline
\end{tabular}

جدول 7. توزيع المبحوثين وفقاً لرأيهم في درجة توافر مستلزمات الإنتاج الحيواني اجمالاً

\begin{tabular}{|c|c|c|c|}
\hline$\%$ & عدد & فئات مستوى التوافر(درجة) & م \\
\hline 10.1 & 19 & منخفض (T - آقل من · (1) & 1 \\
\hline$\varepsilon \cdot . \Lambda$ & $\leqslant 9$ & متوسط (· ( -|قل كم ؛ 1) & r \\
\hline$\varepsilon r . r$ & or & مرتفع (ع ا فأكثر ) & r \\
\hline $1 \cdots$ & Ir. & الإجمالى & \\
\hline
\end{tabular}


جدول V. توزيع المبحوثين وفقاً لمعدل ترددهم على وكلاء التغيير بمنطقة الدراسة

\begin{tabular}{|c|c|c|c|c|c|c|}
\hline \multirow[t]{2}{*}{ الترتيب } & \multirow{2}{*}{ المرجح } & \multicolumn{3}{|c|}{ معدل التردد } & \multirow[t]{2}{*}{ وكيل التغيير } & \multirow[t]{2}{*}{ م } \\
\hline & & حسب الحاجة & كل شهر & كل اسبوع & & \\
\hline 1 & T.. Tr & $\mu$. & 07 & $\mu \varepsilon$ & القادة المحليين & 1 \\
\hline r & I.rT & $\wedge 1$ & rq & . & الطبيب البيطري & r \\
\hline r & $1 . . r$ & $11 \mathrm{~V}$ & r & . & المرشد الزراعى & r \\
\hline \multirow[t]{2}{*}{$\varepsilon$} & $1 . .1$ & 111 & r & . & أخصائي الإنتاج الحيواني & $\varepsilon$ \\
\hline & $1 . r \varepsilon$ & & & & المتوسط المرجح الاجمالي & \\
\hline
\end{tabular}

تثير النتائج الواردة بجدول رقم (9) إلى أن المتوسط

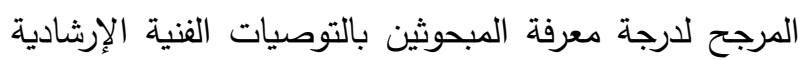

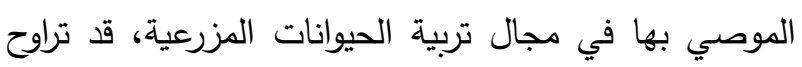

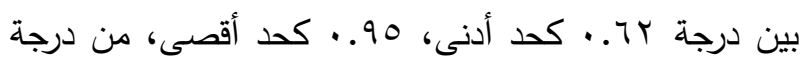
كلية قدرها (واحد) درجة، حيث جاءت كل من: التوصية بتوفير مصدر نظيف لثرب الحيوان، والتوصية بالاهتمام بتطهير حظائر الحيوان ونظافتها، والتوصية بالتهوية الجيدة

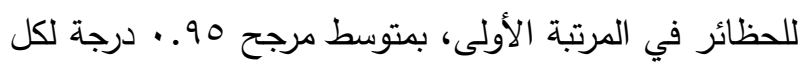

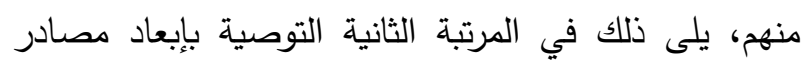

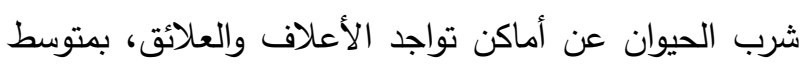

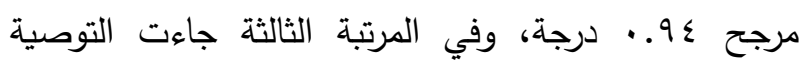

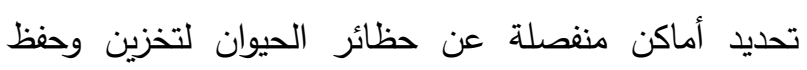
الأعلاف، بمتوسط مرجح به. . . درجة، وفي المرتبة الرابعة جاءت التوصية بجلب سلالات محنة عالئة عالية الإنتاج،

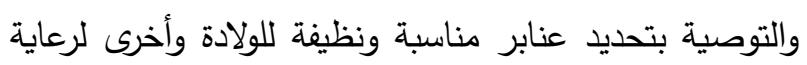

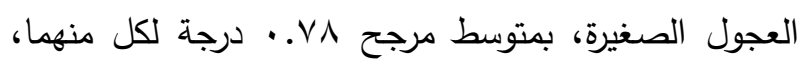

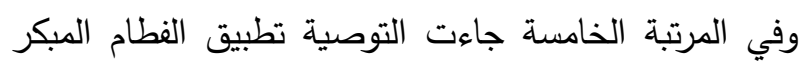

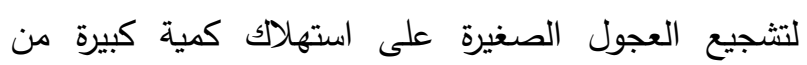

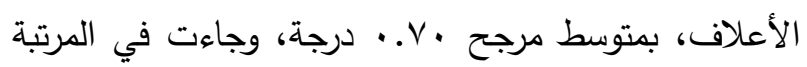
السادسة والأخيرة التوصية عدم اختلاط الحيوانات المختلفة العر والنوع في حظيرة واحدة، بمتوسط مرجح بآ. . . درجة. وقد بلغ المتوسط المرجح الاجمالي 10. • درجة، من درجة درجة

$$
\text { كلية قدرها (واحد) درجة. }
$$

وبتوزيع المبحوثين وفقاً لمعدل ترددهم على وكلاء

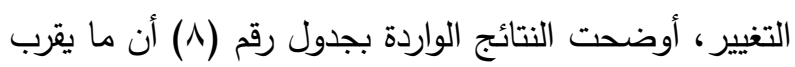

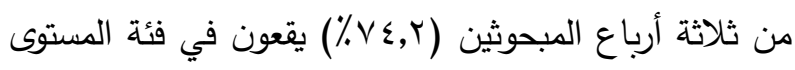

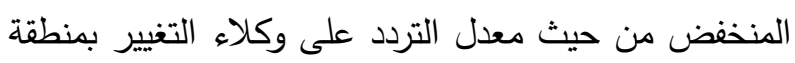

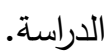

ويتضح مما سبق الانخفاض الواضح لمعدل تردد المبحوثين على وكلاء التغيير بمنطقة الدراسة.

جدول ـ. توزيع المبحوثين وفقاً لمعدل ترددهم على وكلاء التغيير بمنطقة الدراسة

\begin{tabular}{|c|c|c|c|}
\hline$\%$ & عدد & فئات مستوى التردد & م \\
\hline$V \varepsilon, Y$ & 19 & منخفض (r - r T) & 1 \\
\hline r. & $r \varepsilon$ & درجات (ז- - 1) & r \\
\hline $0, \wedge$ & V & فأكثر) (· • ( درجة & r \\
\hline $1 \ldots$ & $1 T$. & الإجمالي & \\
\hline
\end{tabular}

خامسا: مستوي معرفة المبحوثين بالتوصيات الفنية الإششادية في بعض مجالات الإنتاج الحيواني وهي: مجائ التوصيات تربية الحيوانات المزرعية، مجال تغذية الحيوانات المزرعية، ومجال رعايتها. مستوي معرفة المبحوثين بالتوصيات الفنية الإرشادية في مجال تربية الحيوانات المزرعية: 
جدول 9.

\begin{tabular}{|c|c|c|c|c|c|c|c|}
\hline \multirow{3}{*}{ 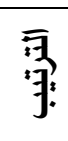 } & \multirow{3}{*}{ 尔 } & \multicolumn{4}{|c|}{ المعرفة } & \multirow{3}{*}{ التوصيات الفنية الإرشادية الموصية الزباتية بها في مجال } & \multirow{3}{*}{ b } \\
\hline & & \multicolumn{2}{|c|}{ لا يعزف } & \multicolumn{2}{|c|}{ يعرف } & & \\
\hline & & $\%$ & 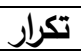 & $\%$ & 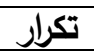 & & \\
\hline$T$ & .90 & 0 & 7 & 90 & $11 \varepsilon$ & توفير مصدر نظيف لشرب الحيوان & 1 \\
\hline 1 & .90 & 0 & 7 & 90 & $11 \leq$ & الآثتماح بتطهير حظائر الحيوان ونظافتها & r \\
\hline 1 & .90 & 0 & 7 & 90 & $11 \leq$ & التهوية الجيدة للحظائر & r \\
\hline r & $.9 \varepsilon$ & 0.1 & $\checkmark$ & $q \leq . r$ & $11 \pi$ & 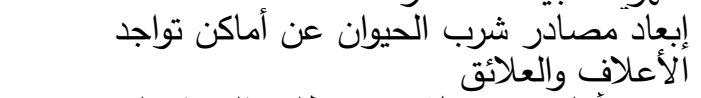 & $\varepsilon$ \\
\hline$r$ & س & $1 V .0$ & YI & NT.O & 99 & تحديد آماكن منفصلة عن حظائر الحيوان لتخزين & 0 \\
\hline$\varepsilon$ & $\because \vee \wedge$ & YT.O & rV & $V \vee .0$ & 94 & جلب سلالات محسنة عالية الإنتاج . & 7 \\
\hline$\varepsilon$ & $\because \vee \wedge$ & r. T.O & TV & $V V .0$ & 94 & تحديد عنابر مناسبة ونظيفة للولادة وآخرى لرعاية & V \\
\hline 0 &.$v$. & r. & ru & $\vee \cdot$ & $\Lambda \varepsilon$ & 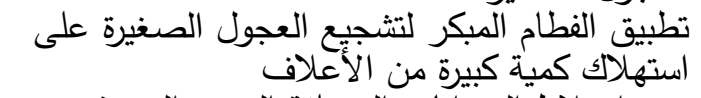 & $\wedge$ \\
\hline 7 &. $.7 Y$ & rᄉ.r & $\leqslant 7$ & $71 . V$ & $V \varepsilon$ & عظدم اختلاط الحيوانات المختلفة العمر والنوع في & 9 \\
\hline &. .10 & & & & & المتوسط المرجح الاجمالى & \\
\hline
\end{tabular}

الموصي بها في مجال تغذية الحيوانات المزرعية، قد تراوح

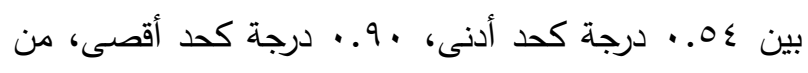

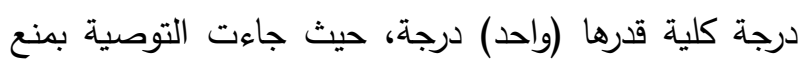
تغذية الحيوانات على الأعلاف الخضراء عند حدوث الإسهال

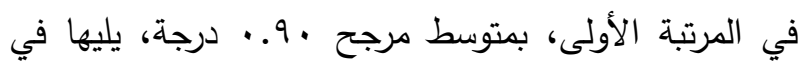

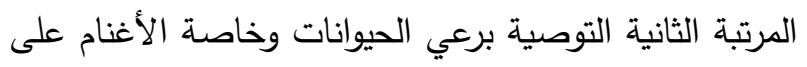
البرسيم بعد تطاير الندى، بمتوسط مرجح AV. . درجة، وفي المرتبة الثالثة جاءت التوصية بتوفير العلائق المتزنة اللازمة للحيوان وخاصة العشار وعجول التسمين، بمتوسط مرجح V^. • . درجة، وفي المرتبة الرابعة جاءت التوصية باعطاء

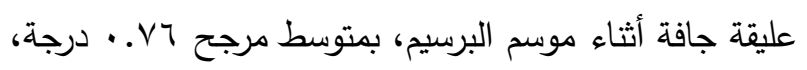

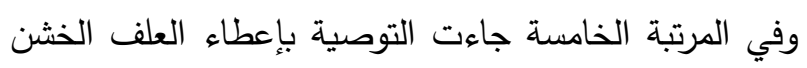
الجاف للتغذية الليلية أثناء شهور الثتاء، بمتوسط مرجح rا.. درجة، وفي المرتبة السادسة والأخيرة جاءت التوصية بالتغذية على علائق متزنة ومفرومة تكون سهلة، بمتوسط وفي مرجح گه. • درجة. وقد بلغ المتوسط المرجح الاجمالي V^ . . درجة، من درجة كلية قدرها (واحد) درجة.
وبتوزيع المبحوثين وفقاً لمستوي معرفتهم بالتوصيات الفنية الإرشادية الموصي بها في مجال تربية الحيوانات المزرعية،

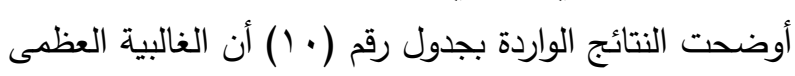
من المبحوثين (^v.0\%) يقعون في فئة مستوى المعرفة فوق المتوسط بالتوصيات الفنية الإرشادية الموصي بها في مجال تربية الحيوانات المزرعية. جدول · ـ ـ ـ التوزيع العددي والنسبي للمبحوثين وفقاً لدرجة معرفته بالتوصيات الفنية الإرشادية الموصي بها في مجال تربية الحيوانات الزراعية

\begin{tabular}{|c|c|c|c|}
\hline$\%$ & عدد & فئات مستوي المعرفة (درجة) & b \\
\hline 1,0 & 10 & منخفض (ع - أقل من 7) & 1 \\
\hline $0 \leqslant, Y$ & 70 & متوسط (ך -أقل من ^) & r \\
\hline س r & $\varepsilon$. & مرتفع (^ فأكثر ) & $r$ \\
\hline $1 \ldots$ & IT. & الإجمالي & \\
\hline
\end{tabular}

مستوي معرفة المبحوثين بالتوصيات الفنية الإرشادية في

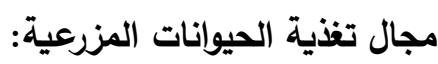
تشير النتائج الواردة بجدول رقم (1') إلى أن المتوسط المرجح لارجة معرفة المبحوثين بالتوصيات الفنية الإرشادية 
جدول 11. توزيع المبحوثين وفقاً لارجة معرفته بالتوصيات الفنية الإرشادية الموصي بها في مجال تغذية الحيوانات

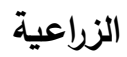

\begin{tabular}{|c|c|c|c|c|c|c|c|}
\hline \multirow{3}{*}{ 雪 } & \multirow{3}{*}{ 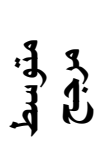 } & \multicolumn{4}{|c|}{ 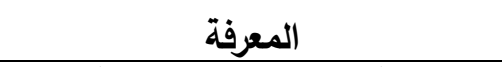 } & \multirow{3}{*}{ 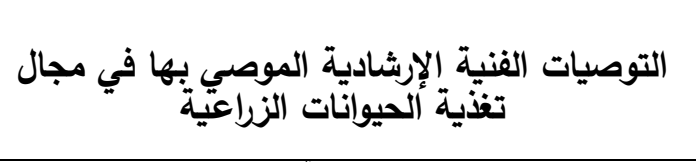 } & \multirow{3}{*}{ م } \\
\hline & & \multicolumn{2}{|c|}{ ل لا يعرف } & \multicolumn{2}{|c|}{ 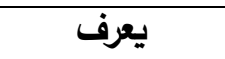 } & & \\
\hline & & $\%$ & تكرار & $\%$ & تكرار & & \\
\hline 1 & $\therefore 9$. & $9 . r$ & 11 & $9 . . \wedge$ & 1.9 & حدوث تغذية الإسيوانات على الأعلاف الخضراء عند & 1 \\
\hline r &.$\wedge V$ & $1 \% .0$ & 10 & NV.O & 1.0 & تطاير الندئى النات وخاصة الأغنام على البرسيم بعد & r \\
\hline$r$ & $\therefore \vee \wedge$ & r..v & $r v$ & $\vee \wedge . r$ & $9 \leq$ & العشأر وعجول التسئق المتزنة اللازمة للحيوان وخاصة & $r$ \\
\hline$\varepsilon$ &..$\vee 7$ & $r \varepsilon . r$ & $r q$ & $\vee 0 . \wedge$ & 91 & إعطاء عليقة جافة آثناء موسم البرسيم & $\varepsilon$ \\
\hline 0 & זT. & rA.r & $\leqslant 7$ & $71 . V$ & $V \varepsilon$ & شهور الثتاء العلف الخشن الجاف للتغذية الليلية أثناء & 0 \\
\hline 7 & $.0 \leqslant$ & $\leq 0.1$ & 00 & $0 \leqslant . r$ & 10 & التغذية على علائق متزنة ومفرومة تكون سهلة & 1 \\
\hline
\end{tabular}

المريض ومراجعة الطبيب البيطري، والتوصية بتطهير

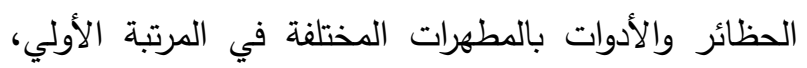

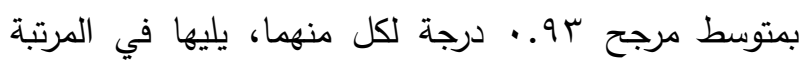
الثانية التوصية بتعريض زجاجات رضاعة العجول لأشعة

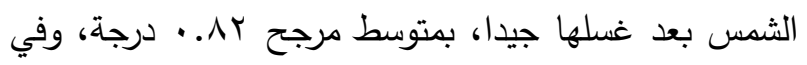
المرتبة الثالثة جاءت التوصية مكافحة الذباب والقوارض

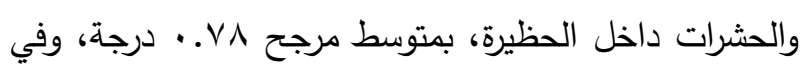

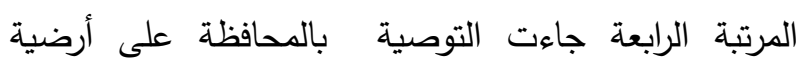

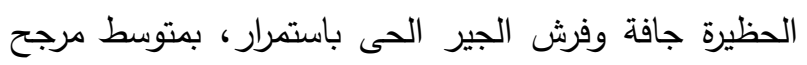

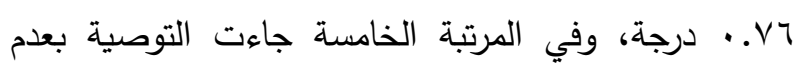

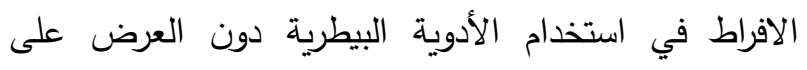

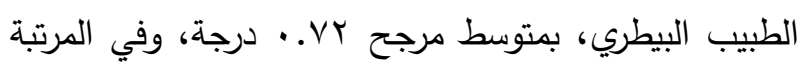

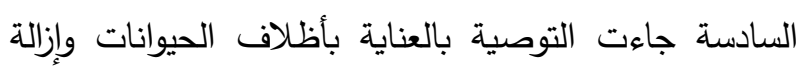

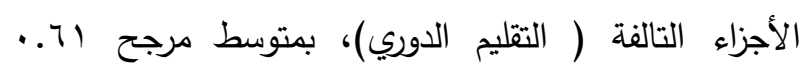
درجة، وفي المرتبة السابعة جاءت التوصية بعدم استخدام

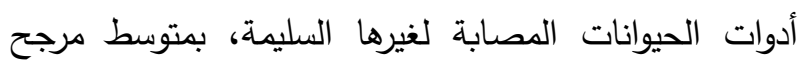

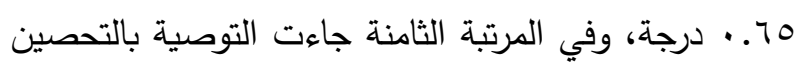

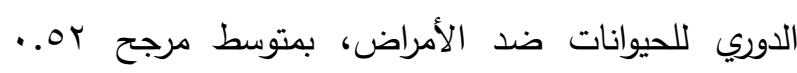

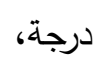

وبتوزيع المبحوثين وفقاً لمستوي معرفتهم بالتوصيات الفنية الإرشادية الموصي بها في مجال تغذية الحيوانات المزرعية،

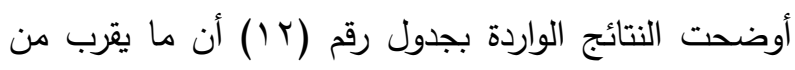

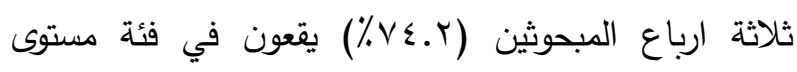

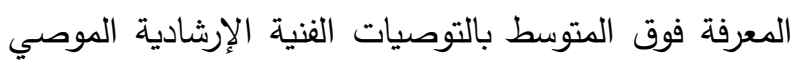
بها في مجال تغذية الحيوانات المزرعية. جدول rا. بات توزيع المبحوثين وفقاً لمستوي معرفتهر بالتوصيات الفنية الإشثادية الموصي بهائ في مجال تغنية

\begin{tabular}{|c|c|c|c|}
\hline \multicolumn{4}{|c|}{ الحيوانات الزراعية } \\
\hline$\%$ & عدد & فئات مستوي المعرفة (درجة) & م \\
\hline ro.1 & $\Gamma$ & منخفض (r- أقل من ؟) & 1 \\
\hline ०9.Y & vi & متوسط (ع - آقل من 7) & r \\
\hline 10 & 11 & مرتفع ('T فآكثر) & r \\
\hline $1 \ldots$ & $T^{T}$. & 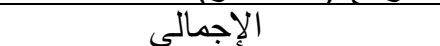 & \\
\hline
\end{tabular}

مستوي معرفة المبحوثين بالتوصيات الفنية الإرشادية في مجال رعاية الحيوانات المزرعية: تثير النتائج الواردة بجدول رقم (r ا) إلى أن المتوسط

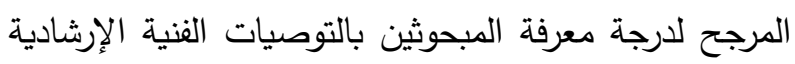

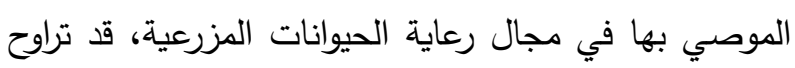

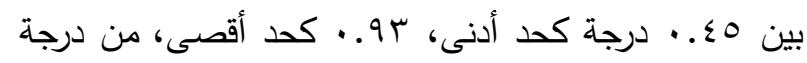
كلية قدرها (واحد) درجة، حيث جاءت التوصية بعزل الحيوان 
جدول ب ا ـ توزيع المبحوثين وفقاً للرجة معرفتهم بالتوصيات الفنية الإرشادية الموصي بها في مجال رعاية الحيوانات الزراعية

\begin{tabular}{|c|c|c|c|c|c|c|c|}
\hline \multirow{3}{*}{ 雪 } & \multirow{3}{*}{ 尔 } & \multicolumn{4}{|c|}{ المعرفة } & \multirow{3}{*}{ التوصيات الفنية الإرشادية الموصي بهاتيات الزياعي مجال } & \multirow{3}{*}{ r } \\
\hline & & \multicolumn{2}{|c|}{ ل الا يعرف } & \multicolumn{2}{|c|}{ يعزف } & & \\
\hline & & $\%$ & 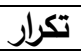 & $\%$ & 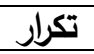 & & \\
\hline 1 & .94 & 7. V & $\wedge$ & $9 \pi .4$ & $11 \mathrm{r}$ & يوان المريض ومراجعة الطبيب & 1 \\
\hline 1 & .94 & 7. V & $\wedge$ & $94 . r$ & $11 \mathrm{r}$ & تظهير "الحظائر والادوات بالمطهرات المختلفة & r \\
\hline r & $\cdot . \wedge r$ & $1 \wedge . r$ & rt & 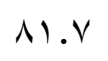 & 91 & & $r$ \\
\hline$r$ & $\cdot \vee \wedge$ & YI.V & rT & VA.r & $9 \leq$ & مكافحة التباب وإلقوارض والحشرات داخل الحظيرة. & $\varepsilon$ \\
\hline$\varepsilon$ &.$V 7$ & rE. & rq & Vo.^ & 91 & ل فرش الجير & 0 \\
\hline 0 &.$V Y$ & rA.r & $r \varepsilon$ & VI.V & $\wedge 7$ & على الطبيب الأبيطري استخدام الأدوية البيطرية دون العرض & 7 \\
\hline 7 &. .71 & rq. r & $\varepsilon V$ & $7 \cdot .1$ & VT & (التنقية بآظلاف الدوري) الحيوانات وإزالة الآجزاء التالفة & $V$ \\
\hline V & $.0 \leq$ & $\leq 0.1$ & 00 & $0 \leqslant . Y$ & 70 & عدم استخدام أدوات الحيوانات المصابة لغيرها السليمة & $\wedge$ \\
\hline$\wedge$ & $.0 r$ & $\varepsilon \wedge . r$ & $0 \wedge$ & $01 . V$ & Tr & التحصين الدوري للحيوانات ضد الآمراض " & 9 \\
\hline 9 &.$\leqslant 0$ & 00 & 77 & $\leqslant 0$ & $0 \leqslant$ & تطهير الجروح مقصات معقمة في عملية جز الاغنام مع & 1. \\
\hline &.$V Y$ & & & & & المتوسط المرجح الإجمالي & \\
\hline
\end{tabular}

يستتتج من النتائج الخاصة بمعرفة المبحوثين بالتوصيات الفنية الإرشادية في مجالات الإنتاج الحيواني المدروسة وهى: مجال تربية الحيوانات المزرعية، ومجال تغذية الحيوانات، ومجال رعايتها، ارتفاع درجة معرفة المبحوثين بهذه التوصيات، حيث بلغ المتوسط المرجح الإجمالي بالنسبة

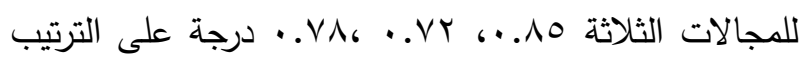
وهى نسبة مرتفعة إذا نسبت للارجة الكلية للمتوسط المرجح لارجة المعرفة وقدرها (درجة واحدة)، كما اتضح أن مستوي معرفة المبحوثين لتلك التوصيات فوق المتوسط أيضاً بنسب

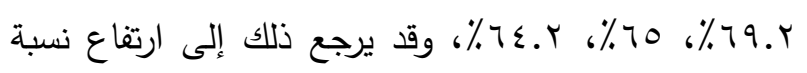

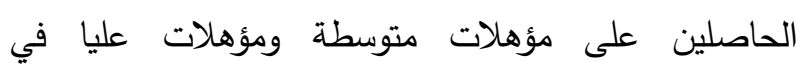

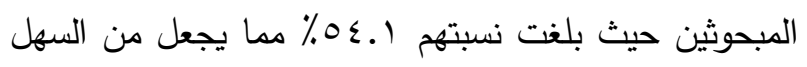
عليهم الحصول على هذه التوصيات من مصادر شتى خاصة مع انتشار التليفونات الذكية التي تساعد في الوصل هلى للمعرفة بطرق سهلة وميسرة.
وفي المرتبة التاسعة والأخيرة جاءت التوصية استخدام مقصات معقدة في عملية جز الاغنام مع تطهير الجروح، بمتوسط مرجح 0؛. . درجة. وقد بلغ المتوسط المرجح الاجمالي VY. . درجة، من درجة كلية قدرها (واحد) درجة. وبتوزيع المبحوثين وفقاً لمستوي معرفتهم بالتوصيات الفنية الإرشادية الموصي بها في مجال رعاية الحيوانات المزرعية، أوضحت النتائج الواردة بجدول رقم (ع ا) أن ما لإنايه يقرب من ثلثي المبحوثين (10\%) يقعون في فئة مستوى المعرفة فوق المتوسط، بالتوصيات الفنية الإرشادية الموصي بها في رعاية الحيوانات المزرعية.

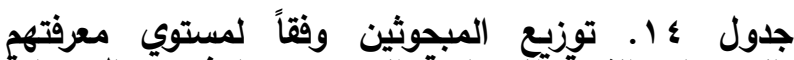

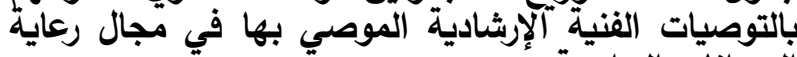
ألهيوانات الزيات الزبية

\begin{tabular}{|c|c|c|c|}
\hline$\%$ & عدد & فئات مستوي المعرفة (درجة) & p \\
\hline ro.. & $\varepsilon r$ & منخفض (ع - أقل من 7) & 1 \\
\hline $01 . V$ & Tr & متوسط (ך - اقل من ^) & r \\
\hline (r. & 17 & مرتفع (^ فأكثر) & $r$ \\
\hline $1 \ldots$ & Ir. & الإجمالي & \\
\hline
\end{tabular}




$$
\text { مجلة الإسكندرية للتبادل العلمى - (مجلد أ العدد () يناير - مارس IY.r }
$$

التوصية بتوفير مصدر نظيف لثرب الحيوان، بمتوسط مرجح I.V.V درجة، وفي المرتبة الرابعة جاءت التوصية

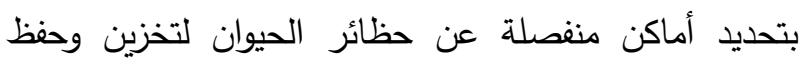

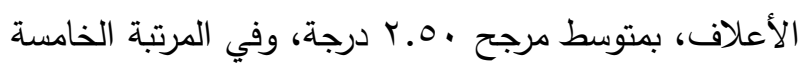

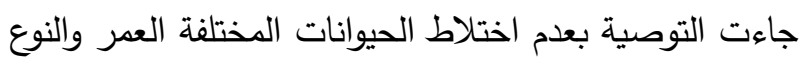

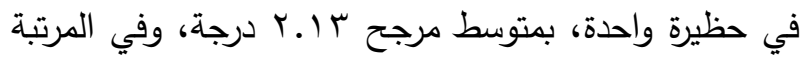
السادسة جاءت التوصية بجلب سلالات محسنة عالية

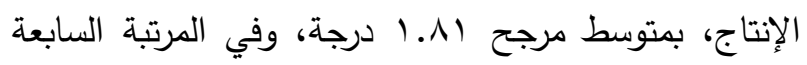
جاءت التوصية بتطبيق الفطام المبكر لتشجيع العجول

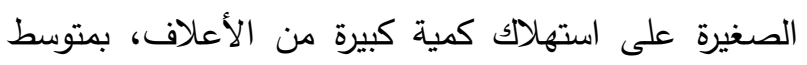
مرجح r I ال درجة، وجاءت في المرتبة الثامنة والأخيرة

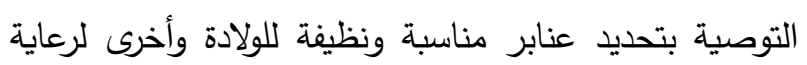

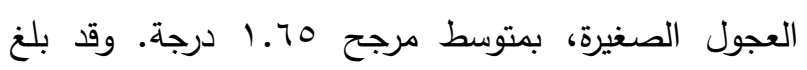
المتوسط المرجح الاجمالي • ·. د درجة، من درجة كلية قدرها

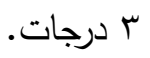

سادساً: درجة تطبيق المبحوثين للتوصيات الفنية الإرشادية في بعض مجالات الإنتاج الحيواني وهي: مجال تربية الحيوانات المزرعية، ومجال تغذية الحيوانات المزرعية،

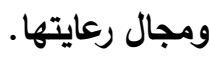
درجة تطبيق التوصيات الفنية الإششادية في مجال تربية

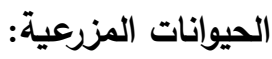

تثير النتائج الواردة بجدول رقم (10) إلى أن المتوسط المرجح لدرجة تطبيق المبحوثين للتوصيات الفنية الإرشادية

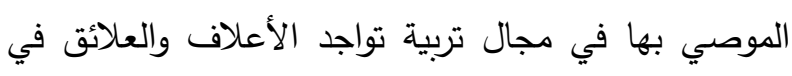

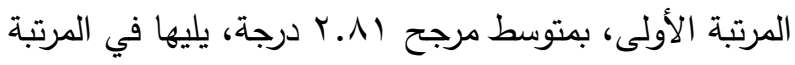
الثانية كل من: ، الحيوانات المزرعية، قد تراوح بين 10

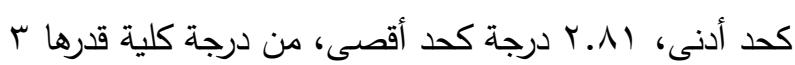
درجات، حيث جاءت التوصية بإبعاد مصادر شرب الحيوان عن أماكن والتوصية بالاهتمام بتطهير حظائر الحيوان

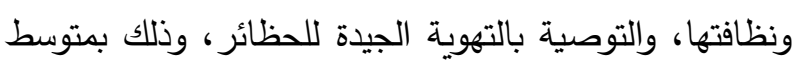

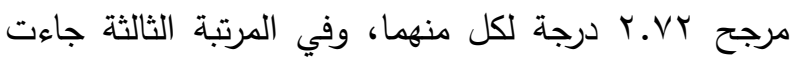

جدول 1 ـ توزيع المبحوثين وفقاً لارجة تطبيقه للتوصيات الفنية الإرشادية الموصي بها في مجال تربية الحيوانات الزراعية

\begin{tabular}{|c|c|c|c|c|c|c|}
\hline \multirow{2}{*}{ 㒳: } & \multirow{2}{*}{ 寺余 } & \multicolumn{3}{|c|}{ فئات التطبيق } & \multirow{2}{*}{ التوصيات الفنية الإرشادية الموصي بهائية في مجال تربية } & \multirow[b]{2}{*}{ p } \\
\hline & & نادراً & أحياناً & دائماً & & \\
\hline 1 & r.A & $\mathrm{v}$ & 9 & $1 \cdot \varepsilon$ & وأبعلادئق مصادر شرب الحيوان عن أماكن تواجد الأعلاف & 1 \\
\hline r & Y.V & 11 & $1 \pi$ & 97 & توفير مصدر نظيف لشرب الحيوان & r \\
\hline r & Y.VY & r & ru & 19 & الاهتمام بتطهير حظائر الحيوان ونظافتها & $r$ \\
\hline r & r.VY & r & rᄉ & 19 & 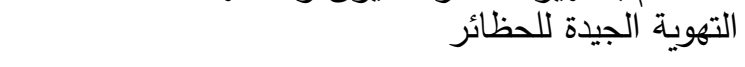 & $\varepsilon$ \\
\hline$\varepsilon$ & r.O. & rt & $1 \varepsilon$ & N & تالعَعلاف أماكن منفصلة عن حظائر الحيوان لتخزين وحفظ & 0 \\
\hline 0 & r.1r & ru & rq & or & واحدة اختلاط الحيوانات المختلفة العمر والنوع في حظيرة & 7 \\
\hline 7 & 1.11 & or & rq & $r \leq$ & جلب سلالات محسنة عالية الإنتاج & v \\
\hline v & $1 . V \Gamma$ & 07 & «1 & r & 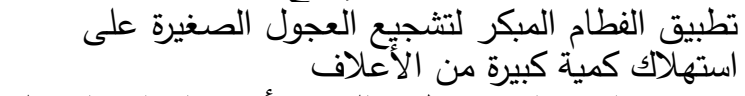 & $\wedge$ \\
\hline$\wedge$ & 1.70 & 00 & or & Ir & تصديد عنابر مناسبة ونظيفة للولادة وأخرى لرعاية العجول & 9 \\
\hline
\end{tabular}


الموصي بها في مجال تغذية الحيوانات المزرعية، قد تراوح

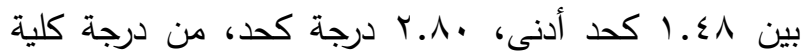
قدرها r درجات، حيث جاءت التوصية بمنع تغذية الحيوانات على الأعلاف الخضراء عند حدوث الإسهال في المرتبة الأولى، بمتوسط مرجح •.^.^ درجة، يليها في المرتبة الثانية التوصية برعي الحيوانات وخاصة الأغنام على البرسيم بعد التاني تطاير الندى، بمتوسط مرجح 94.r درجة، وفي المرتبة الثالثة جاءت التوصية بإعطاء عليقة جافة أثناء موسم البرسيه، بمتوسط مرجح ب.Y.Y درجة، وفي المرتبة الرابعة جاءت التوصية بتوفير العلائق المتزنة اللازمة للحيوان

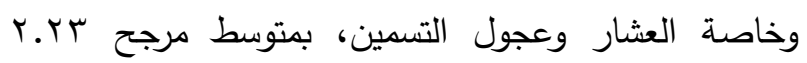
درجة، وفي المرتبة الخامسة جاءت التوصية بإعطاء العلف الخشن الجاف للتغذية الليلية أثناء شهور، بمتوسط مرجح 1.VY Iرجة، وفي المرتبة السادسة والأخيرة جاءت التوصية بالتغذية على علائق متزنة ومفرومة تكون سهلة، وذلك الك بمتوسط مرجح ^^ء.ا درجة. وقد بلغ المتوسط المرجح الاجمالي •Y.r درجة، من درجة كلية قدرها ب درجات.
وبتوزيع المبحوثين وفقاً لدرجة تطبيقهم للتوصيات الفنية الإرشادية الموصي بها في مجال تربية الحيوانات المزرعية،

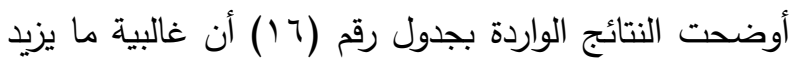

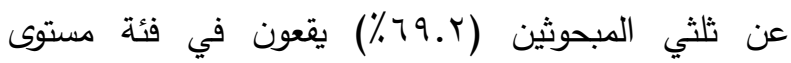
التطبيق فوق المتوسط للتوصيات الفنية الإرشادية الموصي بها في مجال تربية الحيوانات المزرعية.

جدول 14 ـ التوزيع العددي والنسبي للمبحوثين وفقاً لارجة تطبيقهم للتوصيات الفنية الإرشادية الموصي بها في مجال تربية الحيوانات الزراعية

\begin{tabular}{|c|c|c|c|}
\hline$\%$ & عدد & فُنات مستوي التطبيق (درجة) & b \\
\hline$r \cdot, \lambda$ & rv & منخفض ( • - أقل من سا') & 1 \\
\hline$\sum q, r$ & 09 & متوسط (سّ 1 ـ اقل من 74 1) & r \\
\hline r. & $r \varepsilon$ & مرتفع (جَ ( فأكثر) & $\Gamma$ \\
\hline $1 \ldots$ & Kr. & الإج & \\
\hline
\end{tabular}

درجة تطبيق التوصيات الفنية الإرشادية في مجال تغذية

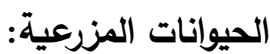

تثير النتائج الواردة بجدول رقم (VI) إلى أن المتوسط المرجح لدرجة تطبيق المبحوثين للتوصيات الفنية الإرشادية

جدول V V. توزيع المبحوثين وفقاً لارجة تطبيقهم للتوصيات الفنية الإرشادية الموصي بها في مجال تغذية الحيوانات الزراعية

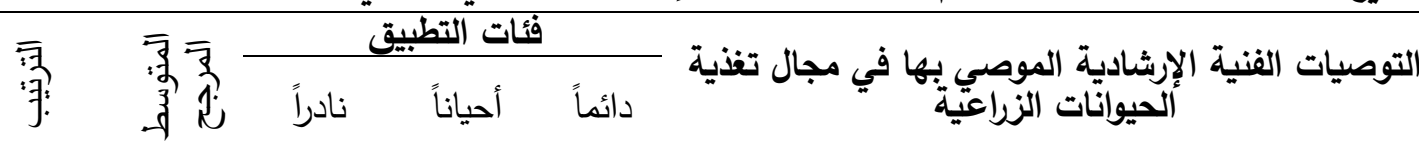

\begin{tabular}{|c|c|c|c|c|c|c|}
\hline 1 & T.A. & 0 & $1 \varepsilon$ & 1.1 & الإسهال تغذية الحيوانات على الأعلاف الخضراء عند حدوث & 1 \\
\hline r & r. 79 & $\varepsilon$ & rq & AV & النذىعى الحيوانات وخاصة الأغنام على البرسيم بعد تطاير & r \\
\hline r & r.rt & rᄉ & IT & 79 & إعطاء عليقة جافة آثناء موسم البرسيح. ــ & r \\
\hline r & r.rT & ro & rr & זיד & وعجولير التسلائق المتزنة اللازمة للحيوان وخاصة العشار & $\varepsilon$ \\
\hline$\varepsilon$ & 1.17 & tr & ro & Tr & الثشاءعاء العلف الخشن الجاف للتغذية الليلية آثناء شهور & 0 \\
\hline 0 & $1 . \varepsilon \wedge$ & VI & r & $\pi$ & التغذية على علائق متزنة ومفرومة تكون سهلة & 7 \\
\hline & T.Y. & & & & المتوسط المرجح الاجمالي & \\
\hline
\end{tabular}


درجة تطبيق التوصيات الفنية الإرشادية في مجال رعاية

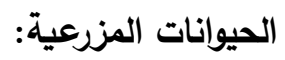

تثير النتائج الواردة بجدول رقم (9 (1) إلى أن المتوسط

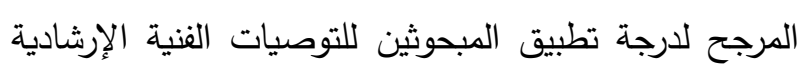

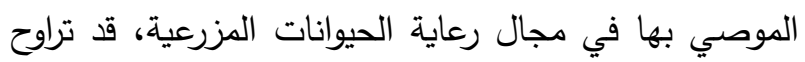

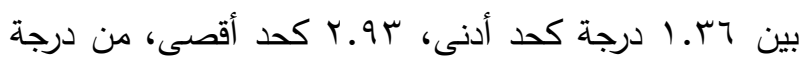
كلية قدرها r درجات، حيث جاءت التوصية بعزل الحيوان

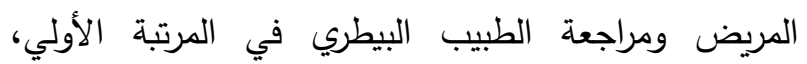

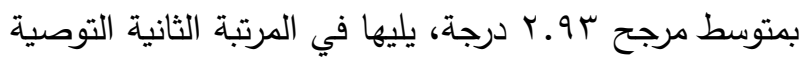
بتطهير الحظائر والأدوات بالمطهرات المختلفة، بمتوسط مرجح •r.A درجة، وفي المرتبة الثالثة جاءت التوصية

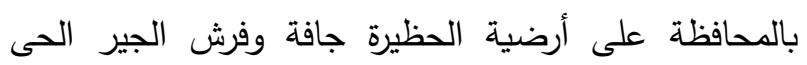
باستمرار، بمتوسط مرجح اـ.Y درجة، وفي المرتبة الرابعة

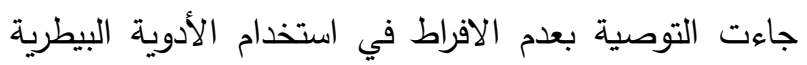

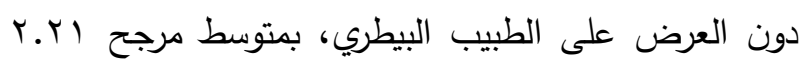

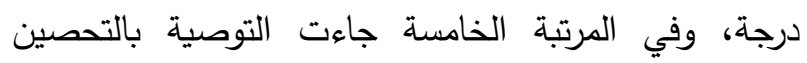

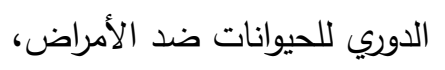

وبتوزيع المبحوثين وفقاً للستوي تطبيقهم للتوصيات الفنية الإرشادية الموصي بها في مجال تغذية الحيوانات المزرعية،

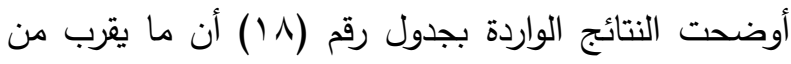

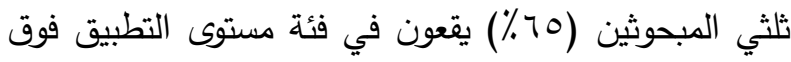

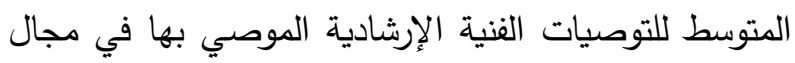
تغذية الحيوانات المزرعية.

جدول 11.. توزيع المبحوثين وفقاً لمستوي تطبيقهم للتوصيات الفنية الإرشادية الموصي بها في مجال تغذية التئ الحيوانات الزراعية

\begin{tabular}{|c|c|c|c|}
\hline$\%$ & 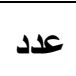 & فئات مستوي التطبيق (درجة) & s \\
\hline ro & $\varepsilon r$ & منذفض (V - أقل من r I ) & 1 \\
\hline 00 & 74 & متوسط (r I - اقل من VI) & $r$ \\
\hline 1. & ir & مرتفع (V ا فاكثر) & \\
\hline $1 \ldots$ & Ir. & الإجمالي & \\
\hline
\end{tabular}

جدول 9 ـ توزيع المبحوثين وفقاً لارجة تطبيقهم للتوصيات الفنية الإرشادية الموصي بها في مجال رعاية الحيوانات الزراعية

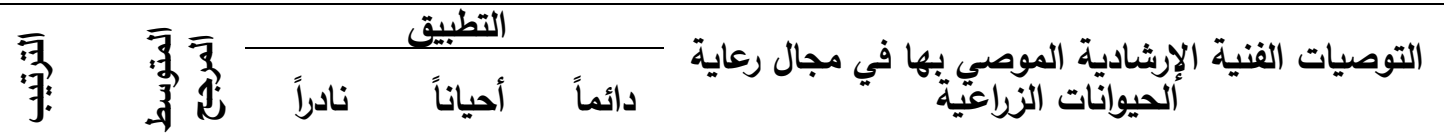

\begin{tabular}{|c|c|c|c|c|c|c|}
\hline 1 & r.9r & 1 & 7 & $11 \pi$ & القيام بعزل الحيوان المريض ومراجعة الطبيب البيطري & \\
\hline r & T.A. & ○ & $1 \varepsilon$ & 1.1 & تطَهير الحظائر والأدوآت بالمطهرات المختلفة & r \\
\hline r & r.乏) & rA & 10 & VV & ل ايرة جافة وفرش الجير الحى & \\
\hline$\varepsilon$ & Y.Y. & rq & IV & $7 \varepsilon$ & على الآفراط في الَيطريخدام الأدوية البيطرية دون العرض & $\varepsilon$ \\
\hline$\circ$ & 1.97 & 01 & 9 & or & التحصين "الدوري" للحيوانات ضد الأمراضِ & 0 \\
\hline 7 & 1.11 & $r \leq$ & Av & 9 & تعريض & 0 \\
\hline v & $1 . \wedge \varepsilon$ & 7. & 19 & $\leqslant 1$ & عدم أستخدام آدوات الحيوانات المصابة لغيرها السليمة. & \\
\hline$\wedge$ & $1 . \Lambda r$ & ov & rV & ru & مكافحة الذباب وآلقوارض والحشرات داخل الحظيرة. & 1 \\
\hline 9 & 1.74 & 70 & r & $r \leq$ & الدوري) باظلاف الحيوانات وإزالة الاجزاء التالفة ( التقليم & 9 \\
\hline 1. & 1.44 & 11 & r) & 11 & تطهير الجروح مقصات معقدة في عملية جز الاغنام مع & 1 . \\
\hline & T... & & & & المتوسط المرجح الاجمالى & \\
\hline
\end{tabular}


وهى: مجال تربية الحيوانات المزرعية، ومجال تغذية الحيوانات المزرعية، ومجال رعايتها، ارتفاع درجة معرفة المبحوثين بهذه التوصيات، حيث بلغ المتوسط المرجح

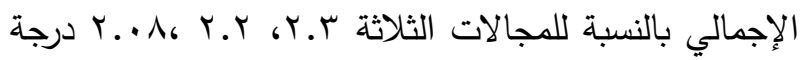
على الترتيب وهى نسبة مرتفعة إذا نسبت للارجة الكلية للمتوسط المرجح لدرجة المعرفة وقدرها ثلاث درجات، كما اتضح أن مستوي تطبيق المبحوثين لتلك التوصيات فوق

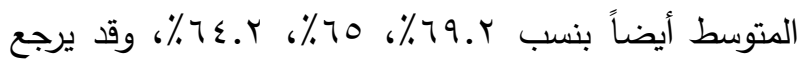
ذلك إلى ارتفاع نسبة المبحوثين اصحاب سنوات الخبرة الطويلة، حيث بلغت نسبة من يقع في المستوى فوق المتوسط لعدد سنوات منهم 7V.0\% وهذا يعنى مرورهم بكثير من التجارب التي تساعدهم في التوصل إلى قناعات بفائدة تطبيق التوصيات الفنية الإرشادية لما يتبع تطبيقها من مردود اقتصادي كبير يساعد في رفع مستوى معيشتهه. سابعاً: تحديد معنوية العلاقة بين المتغيرات المستقلة المدروسة للمبحوثين، وبين درجة تطبيقهم للتوصيات الفنية الإرشادية في بعض مجالات الإنتاج الحيواني. ينص الفرض الإحصائي الثاني على أنه "لا توجد علاقة معنوية بين المتغيرات المستقلة المدروسة للمبحوثين وهي: السن، والحالة التعليمية، وعدد سنوات الخبرة في تربية الحيوانات المزرعية، وحجم الحيازة الحيوانية، ودرجة مشاركتهم في الأنشطة الإرشادية والبيطرية، ودرجة تعرضهم لمصادر المعلومات في مجال الإنتاج الحيواني، وبين درجة تطبيقهم للتوصيات الفنية الإرشادية في بعض مجالات الإنتاج الحيواني وهي: مجال تربية الحيوانات المزرعية، ومجال التغذية، ومجال الرعاية، ولاختبار صحة هذا الفرض تم حساب معامل الارتباط البسيط لبيرسون مع المتغيرات ذات القياس الفتري، ومربع كأي مع المتغيرات ذات القياس

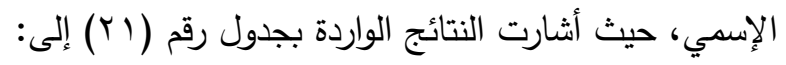
- وجود علاقة طردية معنوية بين درجة تطبيق المبحوثين للتوصيات الفنية الإرشادية في مجالات الإنتاج الحيواني،
بمتوسط مرجح 97 ـ درجة، وفى المرتبة السادسة جاءت التوصية بتعريض زجاجات رضاعة العجول لأشعة الثمس هرس بعد غسلها جيدا، وذلك بمتوسط مرجح 1^.ا درجة، وفي المرتبة السابعة جاءت التوصية بعدم استخدام أدوات

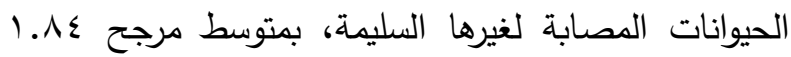
درجة، وفي المرتبة الثامنة جاءت التوصية بمكافحة الذباب والقوارض والحشرات داخل الحظيرة، بمتوسط مرجح سی. درجة، وفي المرتبة التاسعة جاءت التوصية بالعناية بأظلاف

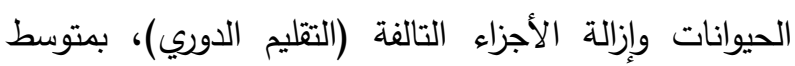
مرجح 17.1 درجة، وفي المرتبة العاشرة والأخيرة جاءت التوصية باستخدام مقصات معقمة في عملية جز الاغنام مع تطهير الجروح، بمتوسط مرجح بس.ا درجة. وقد بلغ المتوسط المرجح الاجمالي ^^.. درجة، من درجة كلية

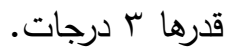

وبتوزيع المبحوثين وفقاً لمستوي تطبيقهم للتوصيات الفنية الإرشادية الموصي بها في مجال رعاية الحيوانات المزرعية، أوضحت النتائج الواردة بجدول رقم (·r) أن ما يزيد عن نصف المبحوثين (Y.؟؟٪) يقعون في فئة مستوى التطبيق فوق المتوسط للتوصيات الفنية الإشادية في مجال رعاية الحيوانات المزرعية.

جدول رقم ·r. توزيع المبحوثين وفقاً لمستوي تطبيقهم للتوصيات الفنية الإرشادية الموصي بها في مجال رعاية الحيوانات الزراعية

\begin{tabular}{|c|c|c|c|}
\hline$\%$ & عدد & فئات مستوي التطبيق (درجة) & b \\
\hline ro.1 & $\varepsilon r$ & منخفض (T I - اقل من اYY) & 1 \\
\hline $07 . V$ & 71 & متوسط (I Y - أقل من YY) & r \\
\hline$V .0$ & 9 & مرتفع (ד r فأكثر ) & $r$ \\
\hline 1. & ir & الإجمالي & \\
\hline
\end{tabular}

يستتج من النتائج الخاصة بتطبيق المبحوثين للتوصيات الفنية الإرشادية في مجالات الإنتاج الحيواني المدروسة 
وبين عدد سنوات خبرتهم في تربية الحيوانات المزرعية، - عدم وجود فروق ذات دلالة احصائية بين تطبيق المبحوثين للتوصيات الفنية الإرشادية في مجالات الإنتاج

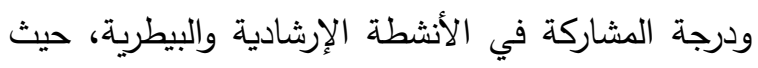
الحيواني، وبين متغير الحالة التعليمية، حيث بلغت قيمة بلغت قيمتا معامل الارتباط البسيط لبيرسون 0 اس. ..، مربع كأي عبو.ب، وهي أقل من نظيرتها الجدولية. •.r... على الترتيب وهما أكبر من نظيرتيهما وعليه فإنه لا يمكن رفض الفرض الإحصائي في الثق الجدوليتان عند مستوى معنوية ا...... الخاص بالتطبيق كلية، وإنما يمكن رفضه بالنسبة لمتغيرات عدد سنوات الخبرة في تربية الحيوانات المزرعية، ودرجة المشاركة في الأنشطة الإشادية، وحجم الحيازة الحيوانية، ودرجة التعرض لمصادر المعلومات في مجال الانتاج الحيواني، والتي ثبتت معنوية علاقتها مع درجة تطبيق المبحوثين للتوصيات الفنية الإرشادية في مجالات الإنتاج الحيواني، مع امكانية رفضه بالنسبة لمتغيري السن، والحالة

- وجود علاقة طردية معنوية بين درجة تطبيق المبحوثين للتوصيات الفنية الإرشادية في مجالات الإنتاج الحيواني، وبين متغيرات، حجم الحيازة الحيوانية، ودرجة التعرض الإنس لمصادر المعلومات في مجال الإنتاج الحيواني، حيث

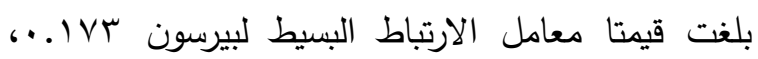

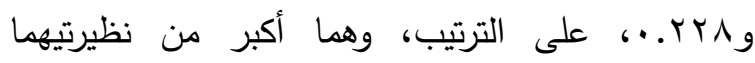
التعليمية. أي أن المبحوثين الأكثر من حيث عدد سنوات الخبرة في تربية الحيوانات المزرعية، وحجم الحيازة الحيوانية، هم الأكثر

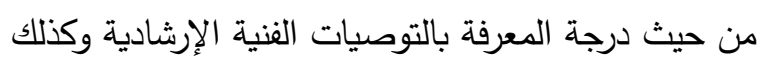
درجة تطبيقهم لهذه التوصيات. الجدوليتان عند مستوى معنوية هـ .... - عدم وجود فروق ذات دلالة احصائية بين تطبيق المبحوثين للتوصيات الفنية الإرشادية في مجالات الإنتاج الحيواني، وبين متغير السن، حيث بلغت قيمة معامل الارتباط البسيط لبيرسون 1 ال..، وهي أقل من نظيرتها

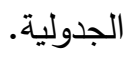

جدول اب . قيم معامل الارتباط البسيط لبيرسون ومربع كأي للعلاقة بين المتغيرات المستقلة المدروسة للمبحوثين، وبين

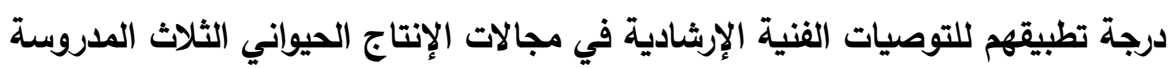

\begin{tabular}{|c|c|c|c|}
\hline المتغير التابع (درجة & الأداة الإحصائية & المتغيرات المستقلة & r \\
\hline. .119 & & 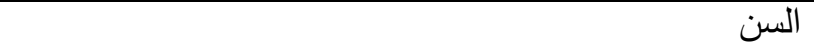 & 1 \\
\hline$* * . M 10$ & & عدد سنوات الخبرة في تربية الحيوانات الزراعية & r \\
\hline$* *$. ro. & بيرسون & درجة المشاركة في الأنشطة الإرشادية & r \\
\hline$* . .109$ & & حجم الحيازة الحيوانية & $\varepsilon$ \\
\hline$* . .19$ & & درجة التعرض لمصادر المعلومات في مجال الإنتاج الحيواني & ○ \\
\hline Y.94 & مربع كأي & 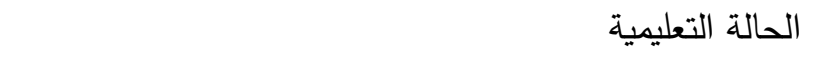 & 7 \\
\hline
\end{tabular}


المختلفة مثل الألبان، وتعدد حلقات سلسلة البيع من المزارع إلى المستهلك النهائي، وعدم مناسبة أسعار بيع المنتجات الحيوانية لمقابلة وتعويض تكلفة الانتاج، واحتفاظ بعض المزارعين بالأساليب التقليدية القديمة في الانتاج الحيواني، مثل استخدام عجل ذكر واحد كطلوقة لجميع الإناث بالقرية،

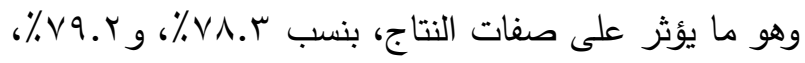

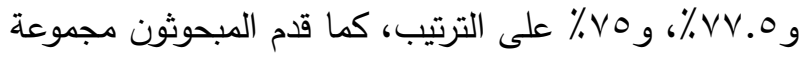
من المقترحات لمواجهة هذه المشكلات، حيث تمثلت أهم المقترحات لمواجهة المشكلات الثلاث الأولى في كل من: دعم أسعار مستلزمات الانتاج الحيواني وتوفيرها عن طريق الجمعية التعاونية الزراعية، ووضع آلية للرقابة على أسعار مستلزمات الانتاج الحيواني بمنطقة الدراسة، وتثديد العقوبة على مزاولة نشاط بيع مستلزمات الانتاج الحيواني بدون تراخيص والعمل على سهولة استخراج رخص الالتحاق بمجال بيع مستلزمات الانتاج الحيواني على أن يكون ممن لهم علاقة مباشرة بمجالات الانتاج الحيواني، وإعادة النظر في سياسة استيراد الرؤوس الحية من حيوانات اللحم واستخدامها في السوق المحلى بما يقلل من الآثار السلبية على مربى ملى السلالات البلدية، والاهتمام بالسلالات البلدية والعمل على تحسين صفاتها، ولمواجهة المشكلات من الرابعة إلى لى لئ

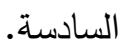

ثامناً: المشكلات التي تواجه الزراع المبحوثين في مجالات الإنتاج الحيواني المدروسة: أوضحت النتائج الواردة بجدول رقم (Yr) أن هناك العديد من المشكلات والتي تواجه الزراع المبحوثين في مجال الانتاج الحيواني، وفيما يلى حصر لأهم هذه المشكلات من وجهة نظر المربين، مرتبة ترتيباً تنازلياً وفقاً للنسبة المئوية

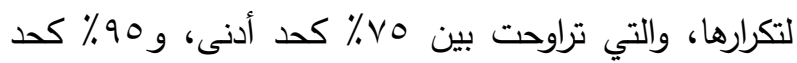
أقصى، حيث جاء في المراتب الثلاث الأولى كل من: ارتقاع أسعار مستلزمات الانتاج الحيواني مثل الأعلاف والأدوية واللقاحات البيطرية، وضعف الرقابة على أسعار مستلزمات الانتاج الحيواني، وزيادة استيراد الرؤوس الحية من حيوانات

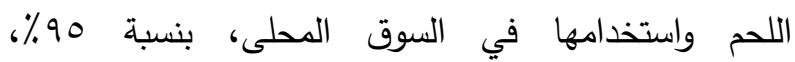

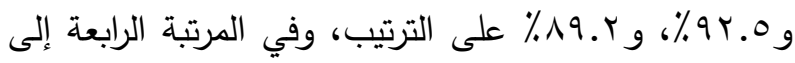
السادسة جاء كل من عدم وجود سياسة تسويقية واضحة المعالم وترك المزارع فريسة للتجار والوسطاء، وصعوبة الحصول على السلالات الحيوانية ذات الانتاجية العالية سواء كانت من اللحم أو الألبان، وضعف الدور الإششادي

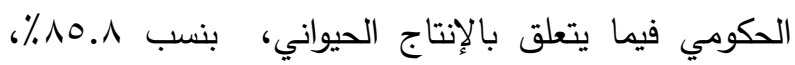

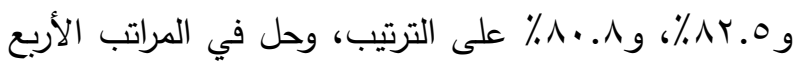
الأخيرة كل من نقص عدد الأطباء البيطريين وقلة تواجدهم بمنطقة الدراسة، وتذبذب أسعار بيع المنتجات الحيوانية

جدول r r. التوزيع التكراري والنسبي للمبحوثين وفقاً للمثكلات التي تواجههم في مجالات الإنتاج الحيواني المدروسة

\begin{tabular}{|c|c|c|c|}
\hline$\%$ & تكرار & 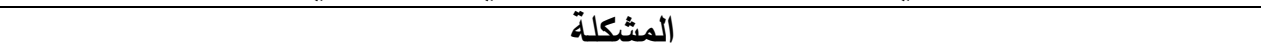 & P \\
\hline 90 & $11 \leq$ & ارتفاع أسعار مستلزمات الانتاج الحيوانى مثل الأعلاف والأدوية واللقاحات البيطرية & 1 \\
\hline 94.0 & 111 & ضعف الرقابة على أسعار مستلزمات الانتاج الحيوا: & r \\
\hline A9. & $1 \cdot v$ & زيادة استيراد الرؤوس الحية من حيوانات اللحم واستذ & r \\
\hline 10.1 & $1 \cdot r$ & عدم وجود سياسة تسويقية واضحة المعالم وترك المز & $\varepsilon$ \\
\hline Ar.o & 99 & صعوبة الحصول على السلالات الحيوانية ذات الانتاجية العالية سواء كانت من اللحم أو الألبان & 0 \\
\hline$\wedge \cdot . \wedge$ & $9 \vee$ & ضعف الدور الإرشادي الحكومي فيما يتعلق بالإنتا & 7 \\
\hline$\vee \wedge . r$ & $9 \leqslant$ & البيطريين وقلَّة تواجدهم بمنطقة آلدراسة & V \\
\hline Vq. & 90 & إلذى الذبتهلك أسعار بيع النهئي النتجات الحيوانية المختلفة مثل الألبان، وتعدد حلقات سلسلة البيع من المزارع & $\Lambda$ \\
\hline$\vee V .0$ & 94 & عدم مناسبة أسعار بيع المنتجات الحيوانية لمقابلة وتعوي & 9 \\
\hline Vo & 9. & 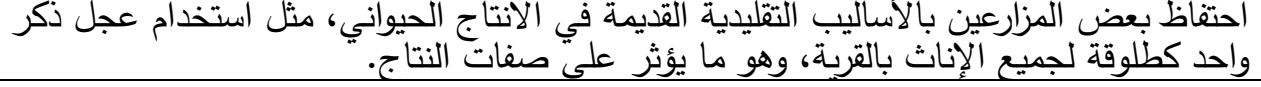 & 1. \\
\hline
\end{tabular}


جدول بr. التوزيع التكراري والنسبي للمبحوثين وفقاً لمقترحاتهم للتظب على المشكلات التي تواجههم في مجالات الإنتاج الحيواني المدروسة

\begin{tabular}{|c|c|c|c|}
\hline$\%$ & 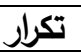 & 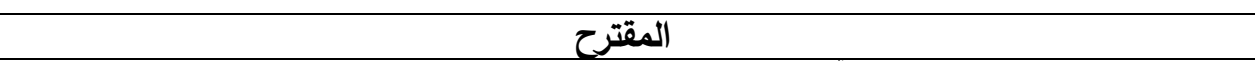 & 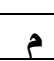 \\
\hline VY.O & $\Lambda \vee$ & وقف استيراد الحيوانات الحية لآنه يؤثر & 1 \\
\hline 70.1 & $\vee 9$ & توفير الحيوانات ذات الانتاجية العالية سواء كانت من اللحم آو الآلبان عن طريق التعاونيات & r \\
\hline 71.7 & $\vee \varepsilon$ & مساعدة المنتجين في تسويق منتجاتهم & r \\
\hline 71.7 & $\vee \leqslant$ & دعم مستلزمات الانتاج الحيواني وتوفير & $\varepsilon$ \\
\hline $7 \cdot . \wedge$ & $\mathrm{Vr}$ & عمل مقر للطبيب البيطري في "الجمعي & 0 \\
\hline ov.o & 79 & ادخال بعض السلالات عالية" الإنتاج بغرض التربية & 7 \\
\hline 07.7 & $7 \Lambda$ & مراقبة أسعار مستلزمات الانتاج الحيواني & $\checkmark$ \\
\hline .0 & 7. & تسهيل استخراج رخص محلات بي & $\wedge$ \\
\hline .0 & & فرض التشليف الإجباري على خريجي الطب البيطري للعملّ في القرى اسوة بخريجي الطب & 9 \\
\hline .0 & 7. & توفير” الخدمة الإرشادية خاصة عن طريق النشرات الفنية & 1. \\
\hline
\end{tabular}

رخص محلات بيع مستلزمات الانتاج الحيواني، ومقترح فرض التكليف الإجباري على خريجي الطب البيطري للعمل في القرى اسوة بخريجي الطب البشري، ومقترح توفير الخدمة

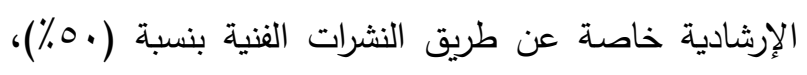

لكل منهم.

\section{التوصيات}

في ضوء ما أسفر عنه البحث من نتائج فانه يمكن وضع

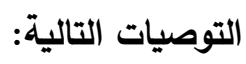

1 - نظراً لما أظهرته نتائج البحث من انخفاض معدل تردد المبحوثين على وكلاء التغيير بمنطقة الدراسة بصورة تعكس وجود النقص الثديد في اعتماد المبحوثين على

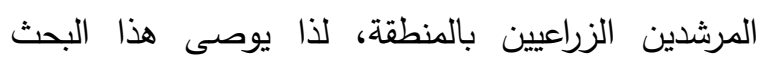

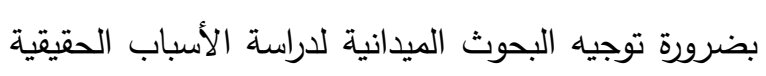
حول هذه المشكلة وبالتالي محاولة وضع مقترح لمواجهتها

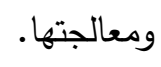

r - نظراً للغياب الكامل لدور الجمعية التعاونية الزراعية في

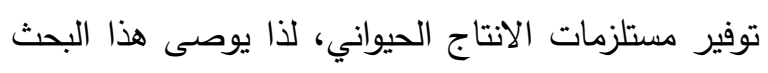
بضرورة رسم سياسة تعاونية تتاسب المنطقة التي تخدمها

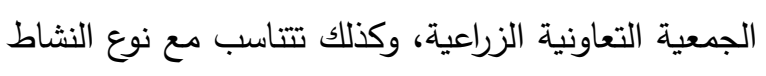

تاسعاً: مقترحات المبحوثين للتغلب على المشكلات التي تواجههم في مجالات الإنتاج الحيواني المدروسة: تم ترتيب مقترحات المبحوثين للتغلب على المشكلات التي تواجههم في مجال الإنتاج الحيواني ترتيباً تتازلياً وفقاً

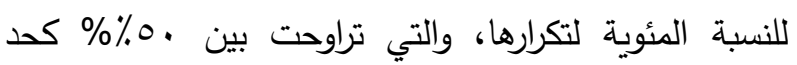
أدنى، و 0Y. \% كحد أقصى، حيث أوضحت النتائج بالجدول رقم (Yr) أن مقترح وقف استيراد الحيوانات الحية لأنه يؤثر على السلالات البلدية جاء في المرتبة الأولي، وفي المرتبة الثانية جاء مقترح توفير الحيوانات ذات الانتاجية العالية سواء كانت من اللحم أو الألبان عن طريق التعاونيات بنسب

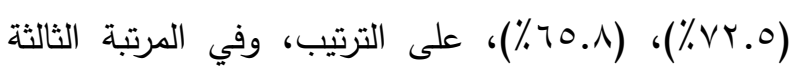
جاء كل من مقترح مساعدة المنتجين في تسويق منتجاتهم،

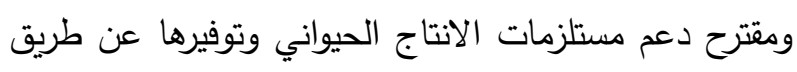
الجمعية الزراعية، بنسبة (7. (7٪\%)، لكل منهما، وفي المرتبة الرابعة جاء مقترح عمل مقر للطبيب البيطري في الجمعية الزراعية، وفي المرتبة الخامسة جاء مقترح ادخال بعض التصاء السلالات عالية الإنتاج بغرض التربية، وفي المرتبة السادسة

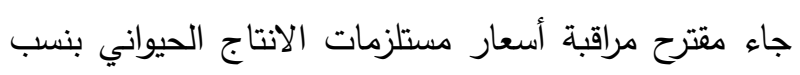

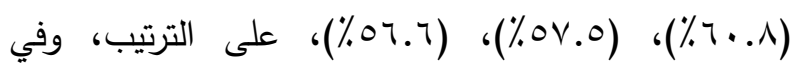
المرتبة السابعة والأخيرة جاء كل من: مقترح تسهيل استخراج 
العلمية للإرشاد الزراعي، المجلد السادس عشر، العدد الرابع.

بالى، عبد الجواد السيد، محمد أبو السعود ربيع (1 (. ب): الخصائص الاجتماعية والاقتصادية للمربين وعلاقتها برعاية ماشية اللبن بالأراضي الجديدة بمحافظة كفر

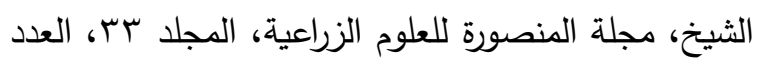

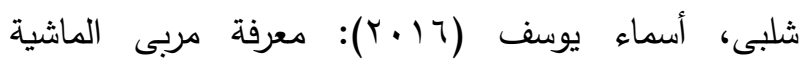
بالإجراءات الوقائية للسيطرة على بعض الأمراض المعدية

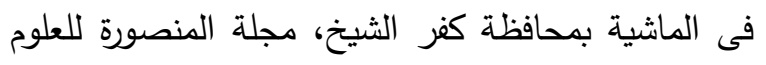

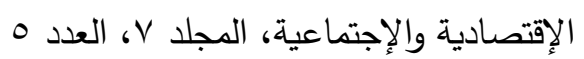
عمر، احمد محمد (ب99 ()): الارشاد الزراعي المعاصر، مصر للخدمات العلمية، القاهرة. قشطة، عبد الحليم عباس (r ( ب): فلسفة الارشاد الزراعي الناجح، جرين لاين للطباعة، القاهرة.

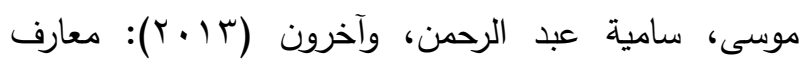

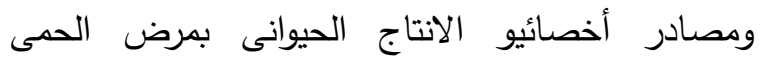
القلاعية بمحافظة كفر الثيخ، مجلة العلوم الاقتصادية

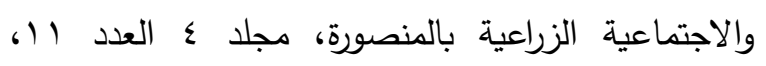

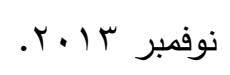

نهى الزاهي السعيد حسن، سمية على العوضي (1 ( • ب): معارف وتوصيات الريفيات بالتوصيات الارشادية لوقاية ماشية اللبن من بعض الامراض المعدية بمحافظة كفر الثيخ، مجلة البحوث الزراعية، جامعة كفر الثيخ، مجلد

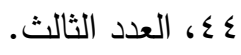

الحيواني الموجود، على أن تقوم الجمعية التعاونية بتوفير

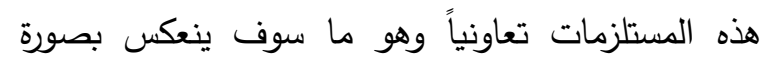
مباشرة على أسعارها. r - أشارت نتائج البحث إلى انخفاض درجة توافر الخدمات المقدمة من الجهات البحثية والإرشادية الزراعية في مجال

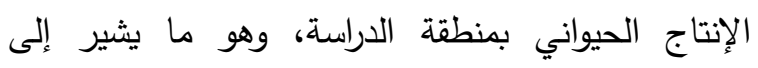

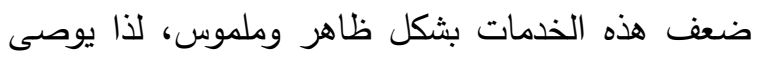
هذا البحث بضرورة التنسيق بين الجهات البحثية والإرشادية الزراعية والتي تقع في نطاق محافظة المنوفية مثل كلية الزراعة بجامعة المنوفية، وكلية الزراعة بمدينة

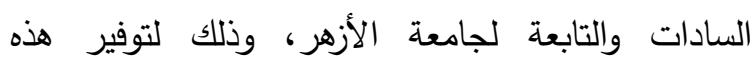
الخدمات من خلالهم للزراع بمنطقة الدراسة، وكذلك تعميم هذه التجربة على مختلف المحافظات. ع - أشارت نتائج البحث إلي وجود مجموعة من المشكلات تواجه الزراع المبحوثين في مجال الإنتاج الحيواني وتؤثر

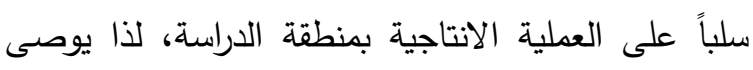

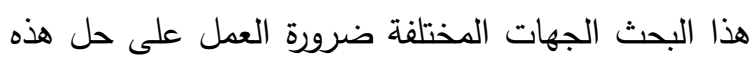
المشكلات كلٌ في مجاله وحسب تخصصس، مع الأخذ في الحسبان مقترحات المبحوثين للتغلب على هذه المشكلات

$$
\text { أو الحد منها. }
$$

\section{المراجح}

الفنية الخاصة بإنتاج اللحم ببعض المراكز فى محافظة البحيرة ، مجلة الإسكندرية للتبادل العلمى- (مجلد 36

$$
\text { العدد 1) يناير - مارس } 2015 .
$$

المليجي، ابتسام بسيوني (Y ( + r): معارف مربى ماشية اللبن ببعض الأمراض التي تصيب الماشية والمتغيرات المؤثرة عليها في بعض قرى محافظة كفر الثيخ، مجلة الجمعية 


\title{
ABSTRACT \\ Knowledge and Implementation by Farmers of Agricultural Advisory Recommendations in the Field of Animal Production in some Villages of Ashmoun Destrict in Menoufia Governorate
}

\author{
Ismail Abdul Malik Muhammad Ismail
}

This research aimed at determining the level of availability of services provided by agricultural research and extension agencies in the field of animal production in the study area, determining the level of availability of animal production requirements, determining the frequency of respondents to change agents in the study area, and determining the level of the respondents 'knowledge of technical advisory recommendations in some areas of animal production studied. These are: the field of raising farm animals, the field of feeding and caring for farm animals, determining the level of respondents 'application of technical advisory recommendations in these studied areas, determining the significance of the relationship between the independent variables studied, and the level of respondents' application of technical advisory recommendations in some areas of animal production studied, and identification On the problems facing the researchers in the field of animal production, and their proposals to overcome them.

This research was conducted on 120 randomly selected respondents by $10 \%$ of the total of 1,200 respondents, representing the number of holders of the villages of Al-Na'naih, Barashim, and Kafr Aoun, which are administratively affiliated with the Ashmoun Center in Menoufia Governorate. The research data were collected in September and October 2020, using A questionnaire form prepared for this purpose, and used to display and statistically analyze data, percentages, tabular presentation by frequency, simple correlation coefficient of Pearson, ki square, mode, and weighted average, using the statistical packages for Social Sciences Statistics. SPSS

It was found that the age pattern of the respondents came in the age group (35 - less than 46 years), and their rate was $51.7 \%$. And that more than half of the respondents $(54.1 \%)$ have an intermediate and higher qualification, more than two-thirds of the respondents (67.5\%) have an above average level of experience in animal production, and that nearly three quarters of the respondents $(69.2 \%)$ fall into The category of the low level in terms of the degree of participation in extension activities, and that the vast majority of respondents $(81.7 \%)$ fall into the small category of the size of the animal holding, and that nearly three quarters of the respondents $(73.3 \%)$ fall into the category of low exposure to information sources in the field of production Animal.

\section{The most important results were as follows:}

It was also found that $(43.3 \%)$ of the respondents believe that the level of availability of animal production requirements in the study area is average, and that the vast majority of respondents (94.2\%) believe that the level of availability of services provided by research and extension agencies is low, and that nearly three quarters of the respondents $(74.2 \%)$ their frequency of change agents is low, and that the majority of the respondents fall into the category of knowledge level above average according to the recommended technical advisory recommendations in each of the fields of breeding, feeding, and caring for farm animals, at rates of $87.5 \%, 74.2 \%$, and $65 \%$ Respectively. It was also found that the majority of them fall in the category of the level of application above average for the recommended technical indicative recommendations in the fields of breeding, feeding and caring for farm animals, with rates of $69.2 \%, 65 \%$ and $64.2 \%$, respectively.

It was also found that there is a significant direct relationship between the degree of the respondents' application of the technical advisory recommendations in the three areas of animal production studied, and between some independent variables studied for the respondents, which are: the number of years of experience in raising farm animals, the size of the animal possession, the degree of participation in extension and veterinary activities, the degree of exposure to sources Information in the field of animal production. The research ended with a set of recommendations, which may be used in improving animal production in the study area. 